Running Head: SOCIAL DYNAMICS WITHIN CLIQUES

The Role of Perceived Popularity and Social Dominance in the Dynamics within Early Adolescent Friendship Cliques

by

Leanna Closson

A thesis submitted to

the Faculty of Graduate Studies and Research

in partial fulfillment of

the requirements for the degree of

Master of Arts

Department of Psychology

Carleton University

Ottawa, Ontario

May 29, 2006

C Leanna Closson, 2006 


$\begin{array}{ll}\begin{array}{l}\text { Library and } \\ \text { Archives Canada }\end{array} & \begin{array}{l}\text { Bibliothèque et } \\ \text { Archives Canada }\end{array} \\ \begin{array}{l}\text { Published Heritage } \\ \text { Branch }\end{array} & \begin{array}{l}\text { Direction du } \\ \text { Patrimoine de l'édition }\end{array} \\ \begin{array}{l}\text { 395 Wellington Street } \\ \text { Ottawa ON K1A 0N4 }\end{array} & \begin{array}{l}\text { 395, rue Wellington } \\ \text { Ottana ON K1A ON4 } \\ \text { Canada Oa }\end{array}\end{array}$

Your file Votre référence ISBN: 978-0-494-18253-6 Ourfile Notre référence ISBN: 978-0-494-18253-6

NOTICE:

The author has granted a nonexclusive license allowing Library and Archives Canada to reproduce, publish, archive, preserve, conserve, communicate to the public by telecommunication or on the Internet, loan, distribute and sell theses worldwide, for commercial or noncommercial purposes, in microform, paper, electronic and/or any other formats.

The author retains copyright ownership and moral rights in this thesis. Neither the thesis nor substantial extracts from it may be printed or otherwise reproduced without the author's permission.
AVIS:

L'auteur a accordé une licence non exclusive permettant à la Bibliothèque et Archives Canada de reproduire, publier, archiver, sauvegarder, conserver, transmettre au public par télécommunication ou par l'Internet, prêter, distribuer et vendre des thèses partout dans le monde, à des fins commerciales ou autres, sur support microforme, papier, électronique et/ou autres formats.

L'auteur conserve la propriété du droit d'auteur et des droits moraux qui protège cette thèse. $\mathrm{Ni}$ la thèse ni des extraits substantiels de celle-ci ne doivent être imprimés ou autrement reproduits sans son autorisation.
In compliance with the Canadian

Privacy Act some supporting forms may have been removed from this thesis.

While these forms may be included in the document page count, their removal does not represent any loss of content from the thesis.
Conformément à la loi canadienne sur la protection de la vie privée, quelques formulaires secondaires ont été enlevés de cette thèse.

Bien que ces formulaires aient inclus dans la pagination, il n'y aura aucun contenu manquant. 


\begin{abstract}
The present study sought to provide an understanding of the role of perceived popularity and social dominance in the dynamics within early adolescents' $(N=387)$ friendship cliques. A status hierarchy between cliques within the larger peer group (based on perceived popularity) and a status hierarchy between individuals within each clique (based on social dominance) were delineated. Significant differences between each level of social status for both hierarchies were found, indicating that the perceived popularity of cliques and the dominance rank of individuals within each clique were related to social behaviour within cliques, likeability as perceived by friends within each clique, and likeability and visibility as perceived by peers. Results suggested that aggressive behaviour used toward friends may be associated with high social status within the clique as well as within the larger peer group. The importance of using a multidimensional conceptualization of social status in understanding social behaviours used within early adolescent friendship cliques is discussed.
\end{abstract}


Table of Contents

Social Status...........................................................................

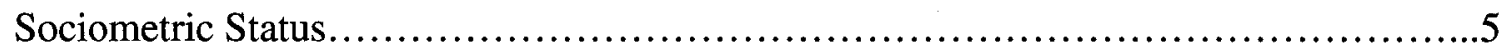

Perceived Popularity...................................................... 7

Social Dominance................................................................... 12

Multidimensional Approach to Social Status...................................... 18

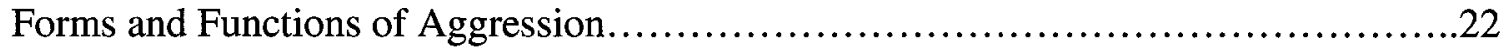

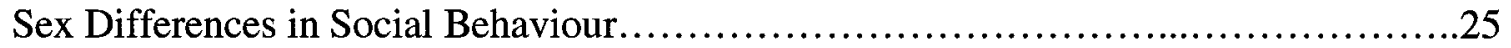

Perceived Popularity and Aggression..............................................26

Perceived Popularity, Social Dominance, and Social Behaviour.......................29

Social Behaviour within Dyadic Friendships..................................... 31

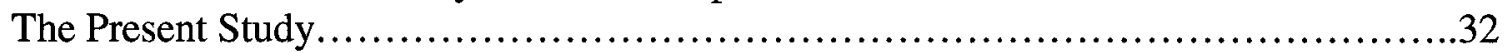

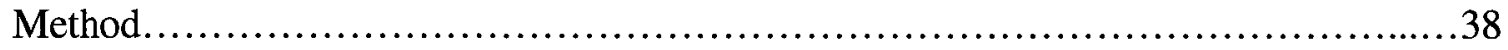

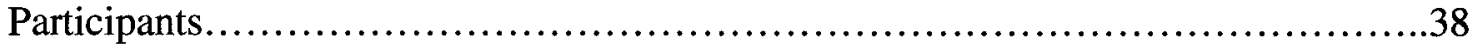

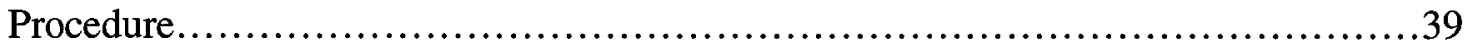

Measures............................................................................

Description of Popularity..................................................40

Nominations List..........................................................40

Perceived Popularity......................................................... 41

Likeability and Visibility .................................................... 41

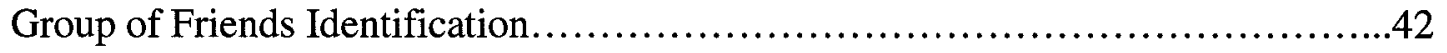

Group of Friends Questionnaire............................................... 45

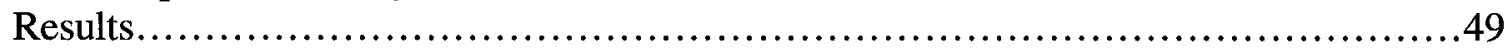

Preliminary Analyses.......................................................49

Descriptive Information about Cliques.........................................52

Perceived Popularity of Cliques.................................................54

Dominance Rank of Individuals within Cliques................................56

Association between Clique Perceived Popularity and Individual Social Dominance...57

Social Behaviour as a Function of Perceived Popularity and Social Dominance.........58

Peer Likeability, Peer Visibility, and Friend Likeability as a Function of Perceived

Popularity and Social Dominance..............................................62

Identification of Dominance Strategies......................................66

Comparisons between Dominance Strategies: Social Dominance, Peer Likeability,

Peer Visibility, and Friend Likeability..........................................67

Definition of Popularity...................................................... 71

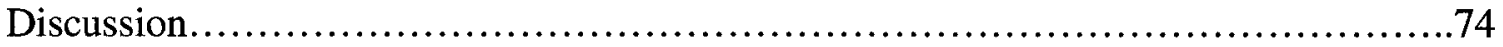

Profile of Individuals in Perceived Popular Cliques............................... 75

Profile of Individuals in Perceived Average Cliques....................................76

Profile of Individuals in Perceived Unpopular Cliques.............................78

Profile of High-Dominant Individuals.......................................... 79

Profiles of Average-Dominant and Low-Dominant Individuals...................8 80

Strategies Used by High-Dominant Individuals: Prosocial, Aggressive, and

Bistrategic. 
Lack of Interaction Effects between Clique Perceived Popularity and Dominance

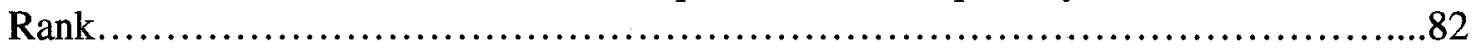

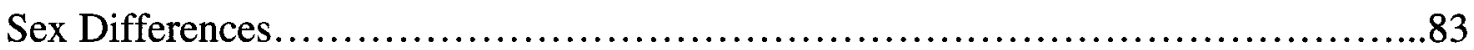

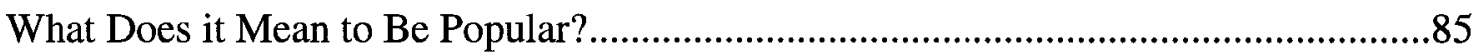

Limitations and Future Directions................................................89

Conclusions...................................................................... 91

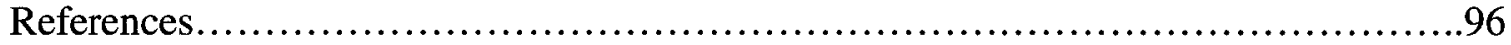




\section{List of Tables}

Table 1: Outline of the Instruments Used to Assess Each Construct....................48

Table 2: Intercorrelations between Major Variables...............................50

Table 3: Means, Standard Deviations, and Ranges for Girls and Boys on Major Variables................................................................53

Table 4: Means and Standard Deviations for Social Behaviour by Clique's

Perceived Popularity ...................................................60

Table 5: Means and Standard Deviations for Social Behaviour by Individual's

Dominance Rank

Table 6: Means and Standard Deviations for Peer Likeability, Peer Visibility, and

Friend Likeability by Clique's Perceived Popularity.

Table 7: Means and Standard Deviations for Peer Likeability, Peer Visibility, and

Friend Likeability by Individual's Dominance Rank.

Table 8: Observed and (Expected Values) for the Chi-Square Test Comparing the Number of Prosocial-Dominant, Aggressive-Dominant, and BistrategicDominant Individuals Who Were Members of Perceived Popular, Perceived Average, and Perceived Unpopular Cliques................................68

Table 9: Means and Standard Deviations for Social Dominance, Likeability, and Visibility by Dominance Strategy of High-Dominant Individuals. .70

Table 10: Frequencies of Words Used to Describe What it Means to be Popular......72-73 
List of Appendices

Appendix A: Informed Consent Letter for Parents/Guardians...................... 107

Appendix B: Parent/Guardian Consent Form................................. 108

Appendix C: Oral Instructions for Students..................................109

Appendix D: Oral Debriefing for Students....................................110

Appendix E: Debriefing Letter for Parents/Guardians...........................111

Appendix F: Questionnaire Packet Cover Page................................112

Appendix G: Description of Popularity......................................113

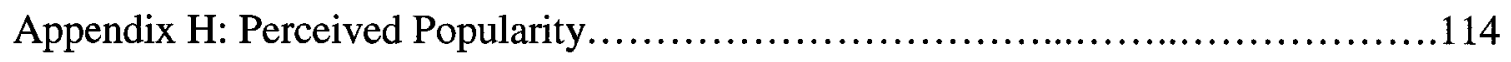

Appendix I: Likeability and Visibility....................................... 115

Appendix J: Group of Friends Identification...................................116

Appendix K: Group of Friends Questionnaire (Friend-Report) $\ldots \ldots \ldots \ldots \ldots \ldots \ldots \ldots \ldots 117$



Appendix M: Directory of Items in the Group of Friends Questionnaire...............127 
The Role of Perceived Popularity and Social Dominance in the Dynamics within Early

\section{Adolescent Friendship Cliques}

From a developmental perspective, positive and negative behaviours have often been considered to be diametrically opposed. The majority of research on the social status of children and adolescents has focused on those who fit into one of two groups: high status individuals who are popular, liked, prosocial, non-aggressive, and socially competent; and low status individuals who are unpopular, disliked, hostile, aggressive, and socially incompetent. However, recent work has begun to show that crossover between behavioural characteristics and outcomes are possible, suggesting that social status is not strictly a bipolar dimension. Recently, researchers have moved beyond exclusively conceptualizing social status in terms of sociometric measures (i.e., likeability and visibility) to exploring perspectives based in sociology (i.e., perceived popularity), and ethology (i.e., social dominance). By utilizing a multidisciplinary approach to measure social status, a more comprehensive understanding of early adolescents' social worlds can be obtained.

Through this all-encompassing lens, researchers have discovered findings that challenge traditional views. For example, aggressive children and adolescents have recently been recognized as a heterogeneous group (Hawley, 2003a, 2003b; Prinstein \& Cillessen, 2003; Rodkin, Farmer, Pearl, \& Van Acker, 2000). In fact, some aggression may be normative and beneficial to social developmental adjustment (Hawley, 2003b; Little, Brauner, Jones, Nock, \& Hawley, 2003), especially if aggression is carefully balanced by the use of prosocial behaviour (Hawley, 2003a, 2003b). These researchers have suggested that aggressive and prosocial behaviours can be used as tools to attain or 
maintain high social status. Despite their use of aggressive behaviours to attain their social goals, these children and adolescents have been perceived positively by teachers, their peers, as well as themselves; therefore, they may potentially be the most socially successful individuals in their peer group. According to ethologists, social dominance is based on the differential abilities between individuals in a group to compete for and obtain desired material and social resources (Hawley, 1999). Socially dominant children and adolescents have been studied within the peer group context (e.g., Hawley, 2002; Lease, Kennedy, \& Axelrod, 2002; Lease, Musgrove, \& Axelrod, 2002; Savin-Williams, 1979) and, less often, within the dyadic friendship context (Koop \& Hawley, 2004). Except for a few ethnographic studies (Adler \& Adler, 1998; Merten, 1997), researchers have yet to explore the behavioural tendencies of socially dominant individuals within their selected group of friends.

Unlike larger peer groups such as classmates or grademates at school, groups of friends or "cliques" are comprised of children who voluntarily associate with one another, and identify one another as friends (Rubin, Bukowski, \& Parker, 1998). In this paper, the term "clique" is used to refer to friendship-based groups of individuals who frequently affiliate with one another. Researchers have shown that, by late childhood, children begin to interact more frequently with friends in their clique than any other peers (Rubin et al., 1998). The prevalence and social influence of cliques has been reported to peak in early adolescence (i.e., grades 6, 7, and 8) (Thompson, O’Neill Grace, \& Cohen, 2001) and have been found to be moderately stable across the school year (Degirmencioglu, Urberg, Tolson, \& Richard, 1998). Since nearly all children and adolescents report being a member of a clique, the social dynamics within this peer 
context may be particularly important to study. Essential questions to be answered in the present study were: how is social status associated with one's behaviour within their friendship clique and how is social status associated with one's likeability by friends and peers?

The paper is structured to provide the reader with a comprehensive review of several bodies of research in order to provide an understanding of how social status has been related to social behaviour and peer perceptions. In the sections to follow, social status is discussed and a description of how it has been conceptualized by developmental psychologists, sociologists, and ethologists in terms of likeability, perceived popularity, and social dominance is presented. A review of the research conducted by those who have taken a multidimensional approach to the study of social status and a description of their findings as they relate to the present study is provided. Then, an overview of the forms and functions of aggression as well as a brief review of the existing literature on the sex differences in aggression and prosocial behaviour is given. Next, a description of the research that has been conducted on the relationship between social status, aggression, and prosocial behaviour is discussed. Finally, the literature on aggression and prosocial behaviour as it occurs within the dyadic friendship context is reviewed. The findings from the research presented provide an indication of how these constructs may relate to the friendship clique context.

\section{Social Status}

Social status exists within the larger peer group as well as within friendship cliques (Cairns, Perrin, \& Cairns, 1985). Status can be perceived as one's individual social reputation as well as one's social reputation based on with whom one affiliates. 
Individual social status within the peer group may be determined by perceived popularity and likeability. As well, entire social groups, such as cliques or crowds, may have reputations based on perceived popularity (e.g., the "Populars"; the "Nerds"). In contrast, social dominance may be an individual characteristic as opposed to a group phenomenon, since only a few individuals can be socially dominant within any given social group (Savin-Williams, 1979).

Both individuals within cliques and cliques within the larger peer group may be organized hierarchically. Within the larger peer group, a status hierarchy implies that perceived popular individuals or cliques have higher social status than perceived average and perceived unpopular individuals or cliques, whereas perceived unpopular individuals or cliques have the lowest social status. Within cliques, a status hierarchy implies that high-dominant individuals have higher social status than those who are average-dominant and low-dominant, whereas low-dominant individuals have the lowest social status. For purposes of this study, the hierarchy of cliques within the larger peer group was determined based on the collective perceived popularity of the individuals who comprised each clique, and the hierarchy within each clique was determined based on the social dominance of each individual clique member. In the present study, perceived popularity was a measure of a clique's social status within the larger peer group as identified by peers, whereas social dominance was a measure of an individual's social status within their clique as identified by the friends in their clique.

In late childhood and early adolescence, social status becomes a central aspect of daily life (Adler \& Adler, 1998; Heilman, 1998; Merten, 2004). Adolescents strongly desire inclusion and acceptance by their peers. They are well aware of the advantages of 
inclusion and high social status and the disadvantages of exclusion and low social status (Merten, 2004). Also, obtaining high social status may be one of the most prominent pathways to self-identification; therefore, achieving it becomes desirable. High social status is important to adolescents because it makes them feel powerful. These high status individuals are well known, highly envied, seen as "cool" by their peers, and are usually the ones who determine the social norms for the entire peer group (Heilman, 1998). Since being perceived as popular and socially dominant is important to many adolescents, some individuals may use any means necessary to achieve and maintain high social status, even at the expense of potentially being disliked by peers (Hawley, 2003b; Merten, 1997, 2004). It may be of importance to early adolescents that they achieve high status positions within their friendship clique in addition to within the larger peer group.

While researchers in related disciplines tend to agree that adolescents are highly concerned with social status, there has been less agreement as to the conceptions of social status and the meaning of popularity (Lease, Kennedy et al., 2002; Lease, Musgrove et al., 2002; Parkhurst \& Hopmeyer, 1998; Rodkin et al., 2000). There are three research traditions concerning social status: psychology-based measures of sociometric status (i.e., likeability and visibility), sociology of education based measures of perceived popularity, and ethology based measures of social dominance. Each of these is discussed in the sections that follow.

\section{Sociometric Status}

Developmental psychologists traditionally measure social status based on how well an individual is accepted by his/her peers. This measure of social status, termed sociometric status, provides an indication of a child's relative likeability and visibility 
within the peer group. Acceptance is determined by the child's number of liked most nominations, whereas rejection is determined by the child's number of liked least nominations (Bukowski \& Hoza, 1989). Sociometric measures also allow individuals to be classified based on social preference (nominations of liked most minus liked least), and social impact (nominations of liked most plus liked least). Social preference is a measure of likeability (Bukowski, Sippola, Hoza, \& Newcomb, 2000) and social impact is a measure of visibility in that peers regard the child with strong opinions, meaning they are either highly liked, highly disliked, or a combination of both (Terry, 2000). Sociometric procedures allow researchers to classify individuals into one of five dimensions of sociometric status: popular, rejected, controversial, neglected, or average.

Sociometric-popular children tend to excel in academics, behave prosocially, and are well liked by their peers. They exhibit low levels of aggressive and disruptive behaviour and low levels of social withdrawal (Newcomb, Bukowski, \& Pattee, 1993). While popular children within the sociometric status literature tend to be leaders, they tend not to impose their social goals on others nor attempt to interfere with the social goals of others (Rubin et al., 1998). Conversely, sociometric-rejected children tend to be reactively aggressive or withdrawn, and disliked by peers (Coie \& Dodge, 1998). Sociometric-controversial children have been shown to display qualities similar to those of both sociometric-popular (e.g., leadership) and sociometric-rejected children (e.g., aggression) and are liked by many as well as disliked by many (Coie \& Dodge, 1988). Finally, sociometric-neglected children are those who are neither rated as liked nor disliked, and tend not to behave prosocially or aggressively (Newcomb et al., 1993). For purposes of the present study, social status was conceptualized as a measure of social 
reputation as opposed to a measure of social preference; therefore, social status was not determined from measures of sociometric status (i.e., participants were not classified into the five sociometric status groups). Rather, visibility and likeability were compared between individuals of differing levels of social dominance as well as between individuals in cliques of differing levels of perceived popularity.

\section{Perceived Popularity}

In contrast to sociometric measurements, sociologists of education study social status using participants' social constructions of popularity. Through ethnographic methods, sociologists have described the profile of those who are perceived as popular by peers to be different than the profile of those who are sociometric-popular. For example, although individuals who are sociometric-popular behave prosocially and are well liked by peers, individuals who are perceived as popular are not necessarily prosocial nor are they always liked by peers (Adler \& Adler, 1998; Eder, 1985; Eder, Evans, \& Parker, 1995; Merten 1997). In order to study the type of popularity that is described by sociologists, developmental psychologists have developed a quantitative measurement. A participant's social construction of popularity has been termed perceived popularity; therefore, the definition of popularity is left up to the participant to determine (Parkhurst \& Hopmeyer, 1998; Lease, Kennedy, et al., 2002; Rodkin et al., 2000). Through this method, participants are asked to nominate "who is most popular" and "who is least popular" (e.g., LaFontana \& Cillessen, 1999). Lease, Kennedy, et al. (2002) argue that by allowing the participant to define "popular," researchers can obtain a more meaningful study than if they impose their own definition. If popularity is indeed a social construction, operational definitions may become outdated by the time data is collected 
since social constructs are sensitive to time and place, as well these definitions may not capture the fundamental nature of popularity in the opinion of all participants.

In their study examining perceived popularity, LaFonatana and Cillessen (2002) interviewed children in grades four through eight and asked them to describe the characteristics of same-sex peers who were perceived as popular. In general, children described perceived popular peers as physically attractive and socially connected. Surprisingly, however, researchers studying perceived popularity have not explicitly asked participants to define the construct of popularity itself. This makes it difficult to draw valid conclusions since researchers cannot be certain as to the essence of the construct being studied. Therefore, one of the goals in the present study was to obtain a definition of popularity as it was understood by the early adolescents in this sample. This provided an indication of whether the conception of perceived popularity is similar among participants.

Perceived popular children may reap more benefits from their high status than those who are sociometric-popular. Lease, Kennedy, et al. (2002) found that peers rated perceived popular children higher than sociometric-popular children on three of four prerogatives associated with high status (i.e., chosen leadership, influence, admiration, and control). While perceived popular and sociometric-popular children were believed to possess the same amount of influence over the entire peer group, peers preferred to have perceived popular children as their leaders. These children were more admired and had more social control than sociometric-popular children.

Even though perceived popularity offers many benefits, there may also be drawbacks. For example, Merten (2004) reported that perceived popularity may often be 
chosen over true friendship. Despite the fact that being perceived as popular may restrict one's friendship choices as well as freedom to express one's feelings, being popular remained desirable. Consequently, the relationships between perceived popular early adolescents may often times be superficial (i.e., they affiliate to maintain high social status not necessarily because they have true feelings of friendship for one another) (Adler \& Adler, 1998). This may not be true of all perceived popular early adolescents; however, these findings suggest that those in perceived popular cliques may not necessarily like one another.

Adler and Adler (1998) suggested that there may be a status hierarchy within the larger peer group. At the top of the peer status hierarchy are the "popular cliques." For purposes of the present study, friendship cliques comprised of perceived popular individuals were termed "perceived popular cliques." Perceived popular early adolescents in these cliques have been described as "cool," powerful, influential, arrogant, exclusionary, elitist, manipulative, controlling, and both overtly and relationally aggressive (Adler \& Adler, 1998; Eder, 1985; Eder et al., 1995; Merten, 1997; Parkhurst \& Hopmeyer, 1998). These individuals were also found to possess savior-faire, which provides them with highly sophisticated interpersonal skills as well as the ability to exploit others (Adler \& Adler, 1998). Perceived popular early adolescents tend to engage in highly visible and prestigious activities such as cheerleading and athletics (Eder et al., 1995), have been found to have a trendy fashion sense, engage in expensive hobbies (Adler \& Adler, 1998), and have been rated as more physically attractive than their peers (LaFontana \& Cillessen, 2002; Lease, Kennedy, et al., 2002). 
Subordinate to the perceived popular cliques in the peer status hierarchy are the "middle friendship circles" (Adler \& Adler, 1998). In the present study, these "middle friendship circles" were termed "perceived average cliques." Early adolescents in these cliques have been described as well-rounded and have healthy relationships with friends. These individuals tend to be nice to all peers, and their friendships are less exclusive and more intimate than those in perceived popular cliques. While early adolescents in perceived average cliques are not immune from aggression within their friendships, it occurs less frequently than within perceived popular cliques (Adler \& Adler, 1998). Parkhurst and Hopmeyer (1998) found that most sociometric-popular early adolescents (i.e., those who were well liked) had average scores on perceived popularity. Therefore, individuals who are in perceived average cliques may be most liked by their peers as well as their friends.

Lastly, according to Adler and Adler (1998), "social isolates" are those at the bottom of the peer status hierarchy. These early adolescents have few friends, and tend to be reactively aggressive or withdrawn. "Social isolates" are generally rejected or neglected by the larger peer group. They are sometimes solitary; however, they occasionally befriend peers at school of similar low status, or often are friends with peers outside of the school setting such as neighbours (Adler \& Adler, 1998). In the present study, the term "perceived unpopular cliques" was used to identify friendship cliques that were comprised of low status individuals such as those described by Adler and Adler (1998).

Researchers who have quantitatively studied perceived popularity have done so at the larger peer group level and have only been concerned with the perceived popularity of 
the individual (e.g., LaFontana \& Cillessen, 2002; Lease, Kennedy, et al., 2002; Parkhurst \& Hopmeyer, 1998). Since sociological researchers have suggested that perceived popularity may be based on the relative status of early adolescents' cliques (Adler \& Adler, 1998), it is important to obtain an evaluation of the perceived popularity of the clique as a whole. A major goal in the present study was to distinguish the status hierarchy of cliques within the larger peer group. In order to achieve this goal, the perceived popularity of each clique was assessed based on the average rating of perceived popularity of the individuals within each clique as rated by peers. The likelihood of individuals within each clique being similar in terms of perceived popularity was high, given that children who are dyadic friends as well as those who "hang around" together have similar levels of perceived popularity (Farmer, Estell, Bishop, O’Neal, \& Cairns, 2003; Rose, Swenson, \& Carlson, 2004). For example, a perceived popular individual is likely to be a member of a perceived popular clique. Therefore, previous research findings that have been conducted based on the perceived popularity of the individual should relate to the perceived popularity of the clique.

Not only may a status hierarchy exist between cliques within the larger peer group, but a status hierarchy between individuals within cliques may also exist (Adler \& Adler, 1998). According to Adler and Adler (1998), at the top of the hierarchy within each clique are "leaders," followed by those who are " 2 nd tier," and lastly those who are "followers." While Adler and Adler (1998) proposed that this hierarchy is more likely to be found within perceived popular cliques, it is possible that similar hierarchies can be found within cliques of any level of perceived popularity. Since an individual's social 
status within cliques was measured in terms of social dominance in the present study, the hierarchy within cliques was referred to as a "dominance hierarchy."

\section{Social Dominance}

Ethologists study the organizational structure within groups (i.e., dominance hierarchy) by assessing the relative social dominance of individuals in the group (e.g., Hawley, 1999; La Freniere \& Charlesworth, 1983; Strayer \& Trudel, 1984). In evolutionary terms, a dominance hierarchy refers to a social system where certain individuals within a group reliably gain greater access than others to key resources (Hawley, 1999). Individuals continually jockey for position in the hierarchy, thus rendering it a dynamic form of social organization. For instance, Savin-Williams (1979) found that within small groups of adolescents at summer camp, most positional changes occurred between lower ranking boys, while first and second ranking boys maintained their position across three months. Comparatively, for girls, positional changes occurred between middle ranking individuals as well as between the top two ranked girls. Due to the fact that a dominance hierarchy may be constantly in flux, any dominance hierarchies found in the present study are reflective of the status quo at the time of data collection. Nevertheless, a dominance hierarchy should exist, regardless of who holds each position at any given time.

Socially dominant individuals are focal members of a group. They are highly visible, influential, and perceived as attractive social partners (Hawley, 1999). Dominant individuals are often respected, cherished, admired, as well as feared. These individuals are generally more socially skilled than the less dominant members of their group. When engaged in a social situation, they are able to assess whether they would succeed in 
obtaining their goals by asserting their dominance or waiting for a more advantageous opportunity (Eisenberg \& Mussen, 1989). Striking differences may be found between the most and the least dominant individuals in a group. The most dominant individual has been characterized as being more liked, athletic, daring, attractive, and socially appropriate than other group members. On the other hand, the least dominant individual is often timid, socially clumsy, passive, hostile, and the least liked individual in a group (Savin-Williams, 1979; Savin-Williams \& Freedman, 1977). Therefore, the most dominant individual and the least dominant individual in each friendship clique may be most dissimilar.

In ethology, an evolutionary perspective is employed to understand the role of aggressive behaviour in achieving and maintaining high social status. Aggression results from within-group competition for access to desired material resources (e.g., the preferred spot in the lunch cafeteria) or social resources (e.g., being deemed the "leader" of the group). Ethologists suggest that aggression is an adaptive function that allows groups of humans and non-humans to establish and maintain dominance hierarchies (La Freniere \& Charlesworth, 1983; Strayer \& Strayer, 1976; Strayer \& Trudel, 1984). From an evolutionary point of view, dominance is a social reward of aggression (Bandura, 1973; Hartup 1974). As well, individuals in dominant positions are regarded as competent and well adjusted (Hawley, 2003b). Within dominance hierarchies, aggression is normally directed toward group members who are at near-adjacent points in the hierarchy (La Frenerie \& Charlesworth, 1983). Therefore, the "alpha" (i.e., highdominant) member of the group often aggresses against group members who are threatening his/her top position in the group, doing so to maintain a high status position. 
This may especially occur once a stable dominance hierarchy has been established. For example, Savin-Williams (1979) found that at the beginning of summer camp, adolescents at the top of the dominance hierarchy tended to exert their dominance, primarily through verbal ridicule, over those who were immediately below them in the hierarchy as well as those who were at the bottom of the hierarchy. However, near the end of the three-month summer camp, dominant adolescents tended to exert their dominance primarily over those who were immediately subordinate to them in the hierarchy. Therefore, it is the high-dominant individuals who are most likely to use aggression within their clique.

In an ethnographic study, Merten (1997) found that the most dominant members of a clique of perceived popular girls used relational aggression against other members of their clique if they felt their dominant positions were being threatened. They often aggressed against those who posed a threat in order to "put them in their place" (p. 179). Similarly, Adler and Adler's (1998) ethnographic study showed that the "leaders" within cliques used aggression against friends who were subordinate to them in the hierarchy. Aside from the present study, no previous research has attempted to replicate these ethnographic findings through quantitative measures.

The traditional ethological view of social dominance insists that dominant individuals use competitive, aggressive, and hostile strategies to attain their goals. However, Hawley (1999) put forth the idea that social dominance is obtained by acquiring resources in a social group, regardless of the means by which it is attained. Using a developmental framework, Hawley (1999) developed "resource control theory," suggesting that one's ability to compete for and control resources (i.e., material resources 
or social resources such as access to social partners, attention from peers, and choice of activities) determines each group member's status within the dominance hierarchy. According to Hawley's (1999, 2001, 2003a, 2003b) research, dominant children and adolescents tend to use one of three strategies of resource control: prosocial (e.g., reciprocity, cooperation, persuasion, and helping behaviours), coercive (e.g., aggression, manipulation, deception, insults, and threats), or bistrategic (i.e., the use of either prosocial or coercive strategies depending on what would bring most success given the context of the particular situation). Hawley argued that all types of strategies can be effective. However, those who use coercion exclusively may begin to lose positive regard from peers by early adolescence, whereas, those who use prosocial strategies should be better able to maintain positive relationships with peers. Therefore, prosocial strategies may be most advantageous in the long term. As well, those who use prosocial strategies are able to successfully acquire social resources (e.g., high social status) while minimizing interpersonal conflict by reciprocating, forming alliances, and cooperating with their peers (Hawley, 2002).

The motivation behind prosocial behaviour is not always altruistic (i.e., motivated by true unselfish concerns); it may also be egoistic (e.g., performed for reward or power) (Eisenberg \& Mussen, 1989). Contrary to the developmental perspective, evolutionary theorists argue that the underlying force behind prosocial behaviour is often self-interest: providing help for others will ultimately help the individual, either by later receiving help in return (reciprocal altruism; e.g., Trivers, 1971), or by having one's reputation bolstered due to a show of altruism. Trivers (1971) suggested that in order to be perceived positively by others, one must not necessarily be genuinely altruistic, but rather, one must 
only appear this way. It is these cunning dominant individuals who are able to reap the most reward while simultaneously receiving social approval from peers. Therefore, prosocial behaviour can be used to secure social dominance in a manner such that both the dominant individual as well as his/her peers can benefit. For example, a dominant adolescent can employ a prosocial strategy such as sharing another adolescent's videogame and playing the game together as opposed to choosing an aggressive strategy such as forcefully taking another adolescent's videogame and playing the game alone. Children and adolescents are highly motivated to access social partners and material resources (Hawley, 1999); therefore, in the example given above, the strategy that provides the highest reward is a prosocial one.

Prosocial dominance is associated with positive social characteristics and outcomes (i.e., perceived as popular, liked by peers, agreeable, conscientious, sensitive to social cues, feelings of connectedness to the peer group, and positive affect) (Hawley, 2003b; Hawley, Little, and Pasupathi, 2002). Comparatively, dominant individuals who exclusively use coercive strategies report high levels of aggressive behaviour, willingness to cheat, and hostility (Hawley, 2003b). These individuals report the most loneliness and negative affect compared to their peers and have a high need for recognition (Hawley et al., 2002). The profile of coercive-dominant individuals is similar to overtly aggressive bullies, which is not surprising given the description of the items assessing coercive control strategies (e.g., "I usually bully or push others to get what I want.") (Hawley, 2003b). However, there may be individuals who utilize a combination of both of these strategies. 
Evolutionary theorists posit that being an accepted member of a group is imperative for a socially dominant individual to assert influence; thus, the use of prosocial strategies should increase the likelihood that an individual will continue to be accepted by their group in spite of aggressive behaviour. A socially dominant individual must decide what appropriate balance of prosocial behaviour and aggression is necessary to maximize his/her reward in order to maintain dominance without being ostracized from the social group (Alexander, 1977). Individuals who use both aggressive and prosocial strategies may hold the highest status position within their clique as well as within the larger peer group. These bistrategic-dominant individuals are socially competent, sharing characteristics and outcomes of prosocial-dominant individuals (e.g., perceived as popular, reasonably liked by peers, agreeable, conscientious, socially skilled, socially integrated, and morally astute) (Hawley, 2003a, 2003b; Hawley et al., 2002) as well as coercive-dominant individuals (e.g., high levels of hostility, loneliness, cheating, and aggression) (Hawley, 2003b; Hawley et al., 2002). Interestingly, teachers perceive these individuals to be non-aggressive, yet through peer- and self-report, bistrategic-dominant individuals are among those who are most instrumentally aggressive (Hawley, 2003b; Hawley et al., 2002), and may prefer the use of relational aggression to overt aggression (Hawley, 2003a). These individuals report the highest need for recognition and highest influence over their peers (Hawley et al., 2002). Bistrategicdominant individuals successfully appear to operate within social norms without necessarily doing so (Hawley, 2003a), fitting the profile of the dominant individuals described by Trivers (1971). If dominant individuals can be identified in a friendship 
clique, it is possible that they employ prosocial, aggressive, or both prosocial and aggressive dominance strategies within their clique.

There may be an overlap in the measurements of sociometric status, perceived popularity, and social dominance. For example, sociometric-controversial children (e.g., Coie \& Dodge, 1988), perceived popular children (e.g., LaFontana \& Cillessen, 2002), and bistrategic-dominant children (e.g., Hawley, 2003a) all share similar characteristics, yet these three similar types of children were identified using three different classification schemes. If a multidimensional approach that combines these three research traditions is employed, a more comprehensive understanding of social status may be obtained.

\section{Multidimensional Approach to Social Status}

A multidimensional, multidisciplinary approach may be very useful in the study of social status. Lease, Musgrove, et al. (2002) identified distinct clusters of children based on their scores on likeability, perceived popularity, and social dominance within the larger peer group. Children were statistically grouped into clusters based on the similarity of their profiles; as such, these clusters were not friendship-based cliques. Nonetheless, this clustering technique may demonstrate that likeability, perceived popularity, and social dominance may collectively play a role in determining an individual's social status.

In the study by Lease, Musgrove, et al. (2002), the clusters with the highest peer status consisted of those who were high status, perceived popular/dominant, and wellliked/dominant. These three clusters of children were socially competent and enjoyed the highest rewards of status (i.e., leadership, coolness, admiration, social control, and influence). High status children (Lease, Musgrove, et al., 2002) may be most similar to 
bistrategic-dominant children (Hawley, 1999) and sociometric-controversial children (e.g., Coie \& Dodge, 1988). These three types of children have been found to be extremely socially sophisticated because they are aggressive and prosocial, yet also reasonably liked. They may use their social skills to find the most effective balance of prosocial and aggressive behaviour that allows them to dominate over their peers. As well, these individuals tend to score high on perceived popularity (Hawley, 2003b; Lease, Musgrove, et al., 2002; Parkhurst \& Hopmeyer, 1998). Well-liked/dominant children (Lease, Musgrove, et al., 2002), children in "middle friendship circles" (Adler \& Adler, 1998), prosocial-dominant children (Hawley, 1999), and sociometric-popular children all share similar characteristics. These children have been shown to be well liked, prosocial, and generally non-aggressive. Perceived popular/dominant (Lease, Musgrove, et al., 2002), and coercive-dominant (Hawley, 1999) children all receive mixed ratings of likeability, and have been rated high on aggression and low or average on prosocial behaviour.

The clusters with the lowest peer status identified by Lease, Musgrove, et al. (2002) consisted of children who were disliked, low dominant/unpopular, and low status. These individuals share similar characteristics with sociometric-rejected children in that disliked children were found to be aggressive and did not value school, while low dominant/unpopular and low status children were found to be withdrawn. These children may not understand the most acceptable ways to behave in the peer group, and therefore, may not possess the appropriate social skills to obtain higher positions in the status hierarchy. 
It is important to note that the study by Lease, Musgrove, et al. (2002) assessed social dominance within the larger peer group, whereas in the present study, social dominance was measured within each clique. Thus, the present study was not a replication of the Lease, Musgrove, et al. (2002) study. However, their results suggest there may be variability in the profiles of individuals within cliques of differing levels of perceived popularity. For example, in their study, individuals who scored high on perceived popularity were all aggressive, yet some were highly prosocial and highly liked, while others were comparatively less prosocial and less liked. Therefore, a dominance hierarchy may exist within cliques since the behaviour and likeability of individuals within each clique may be heterogeneous.

Researchers who have examined aspects of social status among children and adolescents have proposed that although being friends with perceived popular individuals is desirable, perceived popular individuals are not necessarily well liked by their peers (Eder, 1985; Farmer et al., 2003; La Fontana \& Cillessen, 1999; Lease, Kennedy, et al., 2002; Lease, Musgrove, et al., 2002; Merten, 1997; Parkhurst \& Hopmeyer, 1998) or even their teachers (Hopmeyer Gorman, Kim, \& Schimmelbusch, 2002). Recent research findings have suggested that perceived popular children are usually well liked when they are younger, although they are not necessarily well liked as they grow older (Cillessen \& Mayeux, 2004; Kosir \& Pecjak, 2005; La Fontana \& Cillessen, 1999; Parkhurst \& Hopmeyer, 1998). In fact, perceived popularity and likeability appear to become less correlated with age, since the association has been found to be stronger in late childhood (Cillessen \& Mayeux, 2004; Kosir \& Pecjak, 2005; Lease, Kennedy, et al., 2002) than in adolescence (Cillessen \& Mayeux, 2004; Kosir \& Pecjak, 2005; Parkhurst \& Hopmeyer, 
1998). This may be due to adolescents' perceptions that social reputation is distinct and independent from peer preferences (La Fontana \& Cillessen, 1999, 2002). Furthermore, from grade five through grade nine, perceived popularity has been shown to be more stable than likeability (Cillessen \& Mayeux, 2004). If the same individuals are perceived as popular year after year and continue to use aggressive behaviours to maintain their status, it is not surprising that they will be liked less over time.

LaFontana and Cillessen (2002) suggested that as children transition into adolescence, perceived popularity becomes a function of an individual's salience within the larger peer group as opposed to likeability. This age difference may also be due to the fact that perceived popular adolescents are envied greatly by others. As such, envious peers may have mixed feelings toward perceived popular adolescents. Bukowski and Hoza (1989) defined sociometric-popularity as "the experience of being liked or accepted by the members of one's own peer group" (p. 19). This definition is well accepted by developmental researchers; however, according to many children and adolescents, perceived popularity may not be intrinsically defined by likeability. Lease, Kennedy, et al. (2002) and Parkhurst and Hopmeyer (1998) identified children in elementary and middle school, respectively, who were well liked but not perceived as popular, perceived as popular but not well liked, or well liked and perceived as popular. Thus, perceived popularity and likeability are not perfectly correlated nor are they mutually exclusive. In support of this idea, Eder (1985) found through observation and interaction with adolescent females that perceived popular girls were generally not well liked. Similarly, Farmer and colleagues (2003) found that perceived popular children who were predominantly overtly aggressive were disliked despite being perceived as socially 
prominent (i.e., cool, athletic, and leaders). In fact, perceived popular children and adolescents have often been described as "snobbish" and "stuck-up" (Eder, 1985; Hopmeyer Gorman et al., 2002; Parkhurst \& Hopmeyer, 1998). Therefore, perceived popular cliques members may receive mixed ratings of likeability by peers.

Perceived popularity and social dominance have been treated as the same construct by a few researchers (Parkhurst \& Hopmeyer, 1998; Prinstein, 2001). When both constructs are assessed within the larger peer group, perceived popularity and social dominance have been shown to be strongly positively correlated; however, they have each contributed uniquely to our understanding of social status (Lease, Kennedy, et al., 2002). The relationship between social dominance within cliques and perceived popularity within the larger peer group has not been previously examined. Social dominance may be a measurable characteristic an individual exhibits, as opposed to a measure of social reputation or affiliation as is the case with perceived popularity. Nevertheless, perceived popular individuals have been found to be highly dominant within the peer group and often gain and maintain their social status through aggressive strategies (Adler \& Adler, 1998). It is possible that the forms and functions of aggression may vary depending on an individual's dominance rank within his/her clique, as well as the clique's level of perceived popularity within the larger peer group.

\section{Forms and Functions of Aggression}

Aggression can occur through several forms, including overt or direct aggression (i.e., physical and verbal) and covert or indirect aggression (i.e., relational or social). Physical aggression includes acts such as hitting, kicking, punching, and shoving, while verbal aggression includes name-calling and threatening (Coie \& Dodge, 1998). 
Relational aggression (similar to indirect aggression, Bjorkqvist et al., 1992; or social aggression, Galen \& Underwood, 1997) consists of manipulating peer relationships or friendships with the intent to damage a peer's self-esteem and/or social reputation among the peer group (Crick \& Grotpeter, 1995). Examples of relational aggression include spreading rumours, social exclusion, and telling others not be friends with a target child. Relational aggression is particularly effective because the aggressor tends to remain anonymous (Atlas \& Pepler, 1998). The relational aggressor often will manipulate others to "attack" the victim, thus making it unlikely that the aggressor will be confronted with retaliation (Bjorkqvist et al., 1992; Crick \& Bigbee, 1998). Overt aggression and relational aggression are usually moderately or highly positively correlated (Crick \& Grotpeter, 1995; Little, Jones, Henrich, \& Hawley, 2003), although factor analyses provide evidence for their distinctiveness (Crick \& Grotpeter, 1995; Prinstein, Boegers, \& Vernberg, 2001).

These forms of aggression can serve different functions: either instrumental or reactive. Instrumental aggression is used proactively with the intention to achieve one's goals or to obtain materials (Dodge \& Coie, 1987). Interestingly, instrumental aggression has been found to be positively associated with social competence (Little, Jones, et al., 2003), and peer acceptance (Dodge, Coie, Pettit, \& Price, 1990; Price \& Dodge, 1989), especially among other children who also use instrumental aggression (Pellegrini, Bartini, \& Brooks, 1999). Adolescents identified as highly instrumentally aggressive have been found to be academically adept and have positive self-concepts (Little, Brauner, et al., 2003). 
The use of instrumental aggression may be most characteristic of individuals with high social status. Socially dominant individuals have been reported to find frequent success in using instrumental aggression to meet their needs (Strayer \& Strayer, 1976) and often use indirect forms of instrumental aggression to maintain their dominant positions (Savin-Williams, 1980). As well, the perceived popular individuals in Adler and Adler's (1998) study were found to be instrumentally aggressive, using tactics such as coercion, ridicule, social exclusion, and gossip to maintain their high social positions. Furthermore, instrumental relational aggression, especially that which is used to damage social reputation, has been shown to be positively associated with perceived popularity (Prinstein \& Cillessen, 2003). Among individuals in the "Popular" crowd, those who were instrumentally aggressive were rated even higher on perceived popularity (Prinstein, 2001). These findings suggest that, those who are socially dominant and/or perceived as popular may frequently use instrumental aggression, particularly instrumental relational aggression.

In contrast to instrumental aggression, reactive aggression occurs when an individual responds defensively to various situations in an aggressive manner that is often emotionally charged and undercontrolled (Dodge \& Coie, 1987). Instrumental and reactive aggression have been shown to be highly correlated (Dodge \& Coie, 1987; Poulin \& Boivin, 2000; Price \& Dodge, 1989). Nonetheless, after statistically controlling for the forms of aggression, instrumental and reactive aggression have been found to be uncorrelated, suggesting that the functions of aggression are orthogonal constructs (Little, Jones, et al., 2003). This finding reinforces the proposition that different social-cognitive processes are responsible for enacting each function of aggression (Crick \& Dodge, 1994; 
Dodge \& Coie, 1987). Previous research has suggested that reactive aggression derives from an individual's feelings of anger or frustration, and is associated with hostility, frustration intolerance (Little, Brauner, et al., 2003), antisocial behaviour (Little, Jones, et al., 2003), and low status among peers (Adler \& Adler, 1998; Crick \& Dodge, 1994; Dodge \& Coie, 1987; Dodge \& Coie, 1998). These research findings suggest that the form and function of aggression used by individuals may be associated with social status. Sex Differences in Social Behaviour

Examining sex differences in aggressive behavior has become of interest to many researchers. While initial studies on aggression examined boys, more studies have now included girls in their investigations. In the pioneering studies of overt aggression, researchers concluded that boys were more aggressive than girls (e.g., Block, 1983; Maccoby \& Jacklin, 1974). However, once researchers began examining covert forms of aggression (i.e., indirect, relational, and social), they found that boys and girls were equally likely to be aggressive (e.g., Atlas \& Pepler, 1998; Bjorkqvist, Lagerspetz, \& Kaukianinen, 1992; Crick \& Grotpeter, 1995). Some researchers have suggested that boys primarily use physical aggression whereas girls primarily use relational aggression (e.g., Bjorkqvist et al., 1992; Crick \& Grotpeter, 1995; Lagerspetz, Bjorkqvist, Berts, \& King, 1982). Crick and colleagues have often found sex differences where boys are more overtly aggressive than girls, and girls are more relationally aggressive than boys using peer nominations (Crick \& Grotpeter, 1995). However, when self-report measures are used, boys remain more overtly aggressive than girls, but boys and girls tend to be equally relationally aggressive (Crick, 1997). Still, others have shown boys to be more relationally aggressive than girls (Tomada \& Schneider, 1997) and both sexes to be 
equally overtly aggressive (Prinstein \& Cillessen, 2003). These mixed results suggest that researchers must use caution when drawing conclusions from any sex differences observed in their studies.

Few sex differences in the use of aggressive and prosocial strategies have been found among socially dominant individuals. In a study with adolescents at a summer camp, Savin-Williams (1979) found that "verbal ridicule" was the most frequent expression of social dominance for both boys and girls. "Verbal ridicule" involved a combination of verbal aggression (e.g., name calling) and relational aggression (e.g., shunning and ignoring others, talking behind someone's back, gossip, or cattiness about a third person). Socially dominant boys used more overt forms of aggression, whereas socially dominant girls tended to use more prosocial strategies (e.g., complementing others and soliciting advice). However, socially dominant adolescents who use both aggressive and prosocial behaviours (i.e., bistrategic) are equally likely to be boys and girls (Hawley, 2003b).

Studies on the sex differences in social behaviour have provided useful information. More recently, researchers have begun to shift their attention beyond exclusively examining sex differences to focusing on developing functional perspectives and theoretical models to understand the motives and processes that underlie social behaviour (Prinstein \& Cillessen, 2003; Underwood, Galen, \& Paquette, 2001).

\section{Perceived Popularity and Aggression}

Previous developmental research on the use of aggression within the larger peer group has predominantly shown that aggression is associated with rejection by peers (Coie \& Dodge, 1998; Crick, 1996; Crick \& Grotpeter, 1995). This research has only 
conceptualized social status in terms of sociometric measures of likeability; therefore, these findings are not surprising. Recent studies that included measures of perceived popularity in addition to likeability were able to provide new insight on the topic. All forms of aggression have been positively associated with high levels of perceived popularity in adolescence (Cillessen \& Mayeux, 2004; LaFontana \& Cillessen, 2002; Prinstein \& Cillessen, 2003; Rose, Swenson, \& Waller, 2004). Although, Rose, Swenson, and Waller (2004) found that when relational aggression was statistically controlled, the positive association between overt aggression and perceived popularity was nonsignificant; whereas when overt aggression was statistically controlled, the positive association between relational aggression and perceived popularity remained significant. These results, in addition to the strong positive association between overt and relational aggression found in many studies, indicate that perceived popular adolescents tend to be either both overtly and relationally aggressive or exclusively relationally aggressive. The fact that the effect of relational aggression on perceived popularity has been found to double from grade five to grade nine (Cillessen \& Mayeux, 2004) indicates that perceived popular adolescents may be more concerned with maintaining their high status than being liked by their peers.

High levels of perceived popularity may lead to aggressive behaviour more often than the reverse (Cillessen \& Mayeux, 2004). Perceived popularity has been predictive of both overt and relational aggression; however, the relationship between perceived popularity and relational aggression has been particularly strong (Cillessen \& Mayeux, 2004; Rose, Swenson, \& Waller, 2004), especially when relational aggression is used instrumentally to damage someone's social reputation (Prinstein \& Cillessen, 2003). 
During the middle school years, relational aggression has been shown to be predictive of perceived popularity for boys (Cillessen \& Mayeux, 2004) and girls (Cillessen \& Mayeux, 2004; Rose, Swenson, \& Waller, 2004). These findings suggest that children may use aggressive strategies to attain high status; however in adolescence, aggressive strategies may be used to maintain high status.

Social learning theorists have suggested that instrumental aggression is reinforced by social rewards (e.g., high social status); therefore, individuals are likely to continue to use instrumental aggression if they are currently of high status or are ascending in status (Bandura, 1973). Comparatively, reactive aggression may be reinforced in the short term, but use over the long term can restrict opportunities to develop more appropriate and effective strategies to gain social status (Coie \& Dodge, 1998). In fact, Prinstein and Cillessen (2003) showed that reactive overt aggression predicted low peer likeability. Importantly, these findings suggest that aggression, which is used instrumentally, could be a successful tactic to maintain one's high social status, whereas aggression that is used reactively, especially overt aggression, hinders one from increasing social status. Therefore, low status individuals are likely to use reactive aggression, especially reactive overt aggression.

Aggression may be associated with low as well as high levels of perceived popularity. When examining curvilinear trends, Prinstein and Cillessen (2003) found that aggression was associated with low levels of perceived popularity, but to a lesser degree than the association with high levels of perceived popularity. These findings suggest that early adolescents in perceived average cliques may be the least aggressive individuals in the peer group. The majority of research conducted on perceived popularity has focused 
on those who are perceived as popular and those who are perceived as unpopular. Nevertheless, the study by Prinstein and Cillessen (2003) has indicated that analyses involving those who are perceived as average may provide important information. Therefore, in the present study, perceived average cliques were identified and examined in addition to perceived popular and perceived unpopular cliques.

There is evidence that individuals may be aggressive toward those who share similar levels of perceived popularity. Both the aggressors and victims of instrumental aggression, especially reputational forms (i.e., telling rumours and gossiping to damage someone's social reputation), have been shown to be those adolescents who score high on perceived popularity (Prinstein, 2001; Prinstein \& Cillessen, 2003) as well as those in the "Popular" crowd (Prinstein, 2001). These findings suggest that aggression may indeed occur within cliques, especially within perceived popular cliques. These individuals may target other perceived popular adolescents purposefully to damage the reputation of those who may pose a threat to their position within the clique.

\section{Perceived Popularity, Social Dominance, and Social Behaviour}

Perceived popularity has been shown to be associated with prosocial behaviour (Hopmeyer Gordon et al., 2002; LaFontana \& Cillessen, 2002; Prinstein, 2001; Rodkin et al., 2000). Furthermore, the combination of aggression and prosocial behaviour has also been associated with perceived popularity and social dominance. Hawley (1999) suggested that individuals occupying top positions in the dominance hierarchy may do so because they use effective prosocial strategies such as bargaining, compromise, and cooperation as well as aggressive strategies in order to achieve their goals. Hawley's (2001) research examined the use of prosocial and aggressive behaviour, correlating these 
behaviours with likeability. She found that individuals who use aggressive behaviour exclusively tend to be less liked by the peer group. However, individuals who use a combination of aggressive and prosocial behaviour tend to be more liked by the peer group (Hawley, 2001, 2003b; LaFontana \& Cillessen, 2002; Prinstein, 2001).

In adolescence, aggressive peers become more socially attractive (Bukowski, Sippola, \& Newcomb, 2000) and their aggressive behaviour is viewed more positively (LaFontana \& Cillessen, 2002) than in childhood. Therefore, an adolescent who is aggressive as well as prosocial is likely to be viewed positively (i.e., perceived as popular) by those in their clique as well as by peers. For instance, Prinstein (2001) found perceived popular adolescents to be highly aggressive as well as highly prosocial. Members of the "Popular" crowd and members of the "Burnout" crowd were rated high on aggression and perceived popularity; however, only those in the "Popular" crowd utilized prosocial behaviour. Similarly, Rodkin and colleagues (2000) identified two subtypes of perceived popular boys: those who were both perceived popular and prosocial, and those who were both perceived popular and overtly aggressive. While these findings appear to suggest that perceived popular boys are either prosocial or overtly aggressive (implying no overlap between prosocial behaviour and aggression), it is possible that perceived popular boys could be prosocial plus aggressive if relational aggression is assessed, since Prinstein (2001) showed that perceived popular adolescents may use more relational than overt aggression.

Traditionally, aggressive and/or disliked peers have often been considered as socially incompetent. However, when considering perceived popularity and social dominance, a different picture emerges. Social competence has been associated with the 
use of prosocial behaviour and agreeableness; however, it may also be seen in terms of social dominance as the ability to achieve one's personal goals while maintaining positive relationships (Rubin \& Rose-Krasnor, 1992). Aggressive individuals are not usually viewed as socially competent in the developmental psychology literature; however, aggression and social competence may be related for some individuals, especially if they are able to use aggression to successfully achieve their goals without obstructing positive relationships (Hawley, 2002). Many individuals who are perceived as popular and/or socially dominant tend to be aggressive yet they are also prosocial (e.g., Hawley, 2003b; LaFontana \& Cillessen, 2002; Lease, Musgrove, et al., 2002); thus, they are able to attain their social goals without losing their high status. These individuals are socially competent since their use of prosocial behaviour allows them to successfully maintain positive relationships despite their use of aggression. Therefore, all perceived popular clique members and high-dominant individuals in other cliques may use aggressive and/or prosocial behaviours to maintain their high social status.

\section{Social Behaviour within Dyadic Friendships}

Very little research has examined the use of social behaviour within the dyadic friendship context. Nevertheless, this research may provide an indication of what may occur within the clique milieu, since both contexts are based on friendship. Koop and Hawley (2004) showed that individuals who were rated as bistrategic (i.e., both aggressive and prosocial) by their peers were also aggressive within their dyadic friendships. Despite the involvement of conflict in these friendships they were rated as close, fun, and long-lasting. Thus, it is likely that these bistrategic individuals employ similar prosocial strategies toward their friends as they do toward their peers. Children 
who are highly overtly aggressive toward peers tend to have dyadic friendships that involve high levels of conflict (Cillessen, Jiang, West, and Laszkowski, 2005; Rose, Swenson, \& Carlson, 2004) and the use of overt aggression with their friend toward others (Grotpeter \& Crick, 1996; Little \& Card, 2004). However, it is not certain whether these individuals target aggression toward other clique members or outside their clique. Children who are highly relationally aggressive toward peers tend to have dyadic friendships that involve high levels of exclusivity (Grotpeter and Crick, 1996; Little \& Card, 2004), conflict (Cillessen et al., 2005; Rose, Swenson, \& Carlson, 2004; Little \& Card, 2004), as well as relational aggression within their friendship (Grotpeter \& Crick, 1996; Little \& Card, 2004). These findings suggest that, since aggression has been found within a dyadic friendship context, it may be measurable within a friendship clique context as well.

\section{The Present Study}

\section{Goal One}

Sociological researchers have suggested that status hierarchies may exist at two levels: between cliques within the larger peer group and between individuals within each clique (Adler \& Adler, 1998). Within the larger peer group, cliques can be organized hierarchically based on the collective perceived popularity of the individuals who comprise each clique as rated by peers. Within each clique, individuals can be organized hierarchically based on the level of social dominance of each individual within their clique as rated by clique members. To date, no previous quantitative study has used the construct of perceived popularity to delineate a status hierarchy of cliques within the 
larger peer group. As well, no previous study has examined social dominance within cliques. A major goal in the present study was to identify these two types of hierarchies. Hypothesis

When perceived popularity and social dominance were assessed in the larger peer group context, past research has shown a high positive association between these two constructs (Lease, Kennedy, et al., 2002). However, in the present study, the perceived popularity of the clique was assessed by one's peers and the social dominance of the individual was assessed by friends in one's clique. Therefore, I expected these constructs to be independent and the correlation between perceived popularity and social dominance to be low or non-existent. Such a finding would provide support for the distinction of the hierarchy based on perceived popularity separate from the hierarchy based on social dominance.

Goal Two

Another major goal in this study was to examine the social behaviours of individuals within cliques. No previous quantitative study has examined the use of aggression and prosocial behaviour within the context of the clique. It was an aim in the present study to determine if an individual's use of social behaviour within their clique varied as a function of their dominance rank within their clique and/or their clique's level of perceived popularity.

\section{Hypotheses}

Aggression may be associated with low levels of perceived popularity in addition to high levels of perceived popularity. When examining curvilinear trends, Prinstein and Cillessen (2003) found that aggression was associated with low levels of perceived 
popularity, but to a lesser degree than the association with high levels of perceived popularity. As well, Adler and Adler (1998) described those in "middle friendship circles" as virtually non-aggressive. Based on these findings, in the present study, individuals in perceived average cliques were expected to engage in less aggression than individuals in perceived popular and perceived unpopular cliques.

Savin-Williams (1979) found that adolescents at the top of the dominance hierarchy tended to exert their dominance primarily over those who were immediately subordinate to them in the hierarchy, and to a lesser extent, over those who were at the bottom of the dominance hierarchy. Previous research by Hawley (1999) has also suggested that high dominance is associated with increased levels of aggression. Therefore, this study tested the hypothesis that high-dominant individuals would use more aggression within their clique than average-dominant and low-dominant individuals.

Prinstein (2001) found that exchanges of prosocial behaviour were most frequent among members of the "Popular" crowd and least frequent among members of the "Loner" crowd. As well, correlations between perceived popularity and prosocial behaviour were positive yet non-significant. Therefore, I expected those in perceived unpopular cliques would use less prosocial behaviour than those in perceived popular and perceived average cliques.

According to the research by Hawley and colleagues (Hawley, 2003a, 2003b; Hawley et al., 2002), dominant individuals who receive moderate scores on perceived popularity have been shown to be non-aggressive and prosocial. Dominant individuals who receive low scores on perceived popularity have been shown to be aggressive and 
non-prosocial. Dominant individuals who receive high scores on perceived popularity have been shown to be aggressive (especially instrumentally relationally aggressive), and prosocial. Based on Hawley's research, I expected to find that high-dominant individuals in perceived popular cliques would be more instrumentally relationally aggressive than high-dominant individuals in perceived average and perceived unpopular cliques and use more prosocial behaviour than high-dominant individuals in perceived unpopular cliques. I expected high-dominant individuals in perceived average cliques would use more prosocial behaviour than high-dominant individuals in perceived popular and perceived unpopular cliques. Finally, I expected that high-dominant individuals in perceived unpopular cliques would use more overt instrumental aggression than high-dominant individuals in perceived popular and perceived average cliques.

\section{Goal Three}

It was of interest to assess an individual's likeability and visibility as perceived by peers as well as an individual's likeability as perceived by the friends in their clique. It was an aim in the present study to determine if an individual's ratings of likeability and visibility were associated with their dominance rank and/or their clique's level of perceived popularity.

\section{Hypotheses}

The least dominant adolescent in a group has been found to be timid, socially clumsy, passive, hostile, and the least liked individual in a group (Savin-Williams, 1979; Savin-Williams \& Freedman, 1977). Thus, I expected that low-dominant individuals in all cliques would be the least liked individuals in each clique. 
Early adolescents in perceived average cliques have been described to be wellrounded and to have healthy relationships with friends. Individuals in these "middle friendship circles" tend to be nice to all peers, and their friendships are less exclusive and more intimate than those in perceived popular cliques (Adler \& Adler, 1998). Therefore, in the present study, those who were in perceived average cliques were expected to be more liked by their peers as well as their friends than those in perceived popular and perceived unpopular cliques.

Researchers have suggested that perceived popular adolescents are not necessarily well liked by their peers (e.g., La Fontana \& Cillessen, 1999). In fact, perceived popular adolescents may be most similar to sociometric-controversial adolescents (i.e., those who score high on visibility) (e.g., Parkhurst \& Hopmeyer, 1998). Therefore, I expected that individuals in perceived popular cliques would score higher on visibility than individuals in perceived average cliques and perceived unpopular cliques.

\section{Goal Four}

It was of interest to determine whether the type of strategy typically employed by high-dominant individuals was associated with the perceived popularity of their clique. As well, it was of interest to determine whether dominance strategy was associated with likeability and visibility as rated by peers as well as likeability as rated by clique members. It was also of interest to determine whether individuals employing one of the three types of strategies were perceived as equally dominant.

\section{Hypotheses}

According to the research by Hawley and colleagues (Hawley, 2003a, 2003b; Hawley et al., 2002), prosocial-dominant individuals have been shown to receive 
moderate to high scores on perceived popularity, coercive-dominant individuals have been shown to receive moderate to low scores on perceived popularity, and bistrategicdominant individuals have been shown to receive high scores on perceived popularity. Based on Hawley's research, I expected that high-dominant individuals in perceived popular cliques would use primarily bistrategic-dominant strategies; high-dominant individuals in perceived average cliques would use mostly prosocial-dominant strategies; high-dominant individuals in perceived unpopular cliques would use mainly aggressivedominant strategies. Koop and Hawley (2004) have shown that bistrategic-dominant and prosocial-dominant individuals may be more liked by peers than coercive-dominant individuals. Therefore, I expected that bistrategic-dominant and prosocial-dominant individuals may be more liked by peers and friends than aggressive-dominant individuals.

\section{Goal Five}

Previous researchers studying perceived popularity have not explicitly asked participants to define the construct of popularity itself. Therefore, a goal in this study was to obtain a definition of perceived popularity as it was understood by the early adolescents in this sample. Obtaining a definition of perceived popularity should reveal whether most participants were operating from a similar definition.

In sum, the present study examined how the level of perceived popularity of cliques and the dominance rank of individuals within each clique were related to social behaviour within cliques, likeability as perceived by friends within each clique, and likeability and visibility as perceived by peers. This research contributes to the literature by (a) delineating a status hierarchy of cliques within the larger peer group, as well as a dominance hierarchy of individuals within cliques, (b) examining the use of aggression 
and prosocial behaviour within the context of the clique, (c) examining the associations between social status, within-clique behaviour, friend likeability, peer likeability and peer visibility, (d) examining the associations between dominance strategy, clique perceived popularity, friend likeability, peer likeability and peer visibility, and (e) obtaining a definition of perceived popularity as it is understood by the early adolescents in this sample.

\section{Method}

\section{Participants}

Participants included 387 early adolescents (182 males and 205 females) in grades 6 through 8 from three middle schools in a small urban city in western Canada. The overall participation rate for the entire sample was $75 \%$. The participation rates within each grade at each school ranged from $70 \%$ to $89 \%$. Researchers have suggested a minimum consent rate of $60 \%$ when utilizing an unlimited nominations procedure (Nukulkij, Cillessen, Bellmore, Whitcomb, \& Burke, 2002). However, since this study examined the role of each individual within his/her clique, and only participating clique members could be evaluated, it was very important that a high consent rate was obtained. As such, the minimum consent rate was set at $70 \%$ for this study. Each grade at every school achieved a consent rate of at least $70 \%$; therefore, all grades were included in the study. Although information regarding ethnicity and socio-economic status was not collected, the local population consisted primarily of Caucasian, middle socio-economic status families. 


\section{Procedure}

Prior to data collection, I visited each school and spoke to the principal, teachers, and students in each classroom to inform them about the study. Students in participating schools were sent home with a consent letter (Appendix A) describing the study for their parents/guardians and a consent form (Appendix B). Reminder letters were also sent home with those students who did not return consent forms by the deadline indicated on the initial consent form. Additionally, students were reminded daily through morning announcements as well as by classroom teachers to return their consent forms. As an incentive, all students who returned their consent forms, whether they received consent or not, were entered in a draw to win an MP3 player. Eligibility for the draw was based solely on the return of the consent form, not the consent for research itself. The draw was noted in the consent letter for parents/guardians. In addition to the draw for the MP3 player, a pizza party was offered to all classrooms with a one-hundred percent return rate of consent forms, regardless of whether each student received consent. Two classrooms were awarded pizza parties.

Students who received parental permission to participate were administered questionnaires in their classrooms during normal school hours. During data collection, nonparticipating classmates read or worked on homework quietly at their desks, or went to another classroom with a teacher aid. The teacher was asked to remain in the classroom, but was not asked to assist in the data collection. Prior to administration of the questionnaires, participants were orally informed of their right to withdraw from the study at any time. Confidentiality of their responses was also explained. Each questionnaire was presented with written instructions; however, each measure was also 
orally explained to make certain that the participants were clear as to the instructions (Appendix C). Participants were instructed to cover their responses with a piece of paper in order to keep their answers private. A trained graduate researcher remained in the classroom during data collection so as to clarify any questions the participants may have had and ensured that all participants responded to their questionnaires independently. Following completion of the questionnaires, all participants were orally debriefed (Appendix D). As well, participants were given a debriefing letter (Appendix E) to take home to their parents/guardians.

\section{Measures}

The cover page of the questionnaire packet assessed information about grade, school, age, and sex (Appendix F). It also reminded participants of the confidentiality of their responses.

Description of Popularity. One of the purposes in this study was to obtain a better understanding of perceived popularity. In assessing perceived popularity, the definition of popularity is constructed in the mind of the participant (Lease, Kennedy, \& Axelrod, 2002). In only one previous study examining perceived popularity have researchers asked participants to describe characteristics of perceived popular same-sex peers (LaFontana \& Cillessen, 2002); however, researchers have not previously asked participants to provide a definition of the construct of popularity itself. Therefore, participants were instructed to list up to six words describing what popularity means to them (Appendix G).

Nominations List. To complete several nomination measures in this study, participants nominated grademates using a list of students in their grade who were participating in the study. Consistent with ethical requirements, only those adolescents 
who received parental consent to participate were included on the list. The names on the list were printed in multiple columns, arranged by classroom, and were alphabetized by first name. A corresponding identification number was printed beside each name. To nominate a student, participants were instructed to write the student's corresponding identification number in the appropriate space on the questionnaire.

Perceived Popularity. Similar to past researchers (e.g., Cillessen \& Mayeux, 2004; Kosir \& Pecjak, 2005; Lease et al., 2002; Prinstein \& Cillessen, 2003), participants viewed the list with the names of their participating grademates and nominated an unlimited number of peers as (a) most popular ("students who you think are most popular") and an unlimited number of peers as (b) least popular ("students who you think are least popular"). Although ten spaces were provided on the questionnaire for each measure, participants were informed they could nominate more than ten grademates (Appendix H). Numbers of "most popular" and "least popular" nominations received for each participant were separately summed and standardized within grade and school. "Most popular" $z$-scores minus "least popular" $z$-scores were then calculated and the resulting score was restandardized within grade and school to result in a continuous measure of perceived popularity for each participant (Cillessen \& Mayeux, 2004; Prinstein \& Cillessen, 2003). Cillessen and Mayeux (2004) have found the level of an individual's perceived popularity to be highly stable over the course of four years (i.e., grade five through grade nine).

Likeability and Visibility. Consistent with LaFontana and Cillessen (2002), participants viewed the list of participating grademates and nominated an unlimited number of peers who they (a) like most ("students who you personally like the most") and 
an unlimited number of peers who they (b) like least ("students who you personally like the least"). Although ten spaces were provided on the questionnaire for each measure, participants were informed they could nominate more than ten grademates (Appendix I). Numbers of "like most" and "like least" nominations received for each participant were separately summed and standardized within grade and school. "Like most" $z$-scores minus "like least" $z$-scores were calculated and the resulting score was restandardized within grade and school to result in a continuous measure of peer likeability (i.e., social preference) for each participant. "Like most" $z$-scores plus "like least" $z$-scores were calculated and the resulting score was restandardized within grade and school to result in a continuous measure of peer visibility (i.e., social impact) for each participant (Coie, Dodge, \& Coppotelli, 1982). Coie and Dodge (1983) have found the short-term stability for this sociometric technique to be acceptable.

Consistent with recent research (Cillessen \& Mayeux, 2004; Kosir \& Pecjak, 2005; LaFontana \& Cillessen, 2002; Rose, Swenson, \& Waller, 2004), same-sex and cross-sex nominations were allowed in order to identify the most salient individuals who fit the descriptors, regardless of sex. Additionally, nominations were unlimited since previous research has found that unlimited nominations yield a wider range of scores that are less skewed than limited nominations (Terry, 2000).

Group of Friends Identification. Cliques were identified using a modification of the procedures set forth by Paxton, Schutz, Wertheim, and Muir (1999). Using the list of participating students in their grade, participants were instructed to identify the students who are in their clique ("students who are in the group of friends you hang around with most often") (Appendix J). To identify a student from the list as belonging to the 
participant's clique, participants were instructed to write the student's corresponding identification number in the appropriate space on the questionnaire. Participants were also asked to number each of their friends directly on the list of students in their grade. This allowed participants to easily recall which friends they were to rate in the next measure (i.e., the Group of Friends Questionnaire), since no names were written on the questionnaires. The friend who they marked with a " 1 " on the list was the individual they rated as "Friend 1" in the Group of Friends Questionnaire and so on for all friends. In the event that a friend was not participating in the study, participants were allowed to identify non-participating friends by writing their friend's initials in the space provided. An important reason to allow this option for participants was to minimize the risk of a child feeling as though he/she does not have any friends. However, consistent with ethical requirements, participants were instructed not to complete the Group of Friends Questionnaire (Friend-Report) on friends who were not on the list. It was expected that all participants would nominate at least one peer as a friend (Parker \& Asher, 1993). In order to allow for the identification of mixed-sex and same-sex cliques, participants were instructed to write "M" (male), or "F" (female) behind their friend's corresponding identification number on the questionnaire. Because cliques generally range in size from three to ten members (Ennett, Bauman, \& Koch, 1994; Paxton et al., 1999; Rubin et al., 1998), participants were instructed to list not more than nine friends. If their clique consisted of more than ten friends (including themselves), participants were to choose nine of their friends in the clique they spend the most time with. Based on previous research, it was expected that the majority of participants would nominate two to five friends (Paxton et al., 1999). If a participant nominated only one friend (i.e., a group of 
two) they completed the Group of Friends Questionnaires on that friend. However, only cliques of three or more participating individuals were included in analyses. Friendship clique nomination data were analysed using the UCINET 6.0 statistical package (Borgatti, Everett, \& Freeman, 2002). By identifying clusters around mutual friendship ties, the program generated a list of all possible cliques. Since the program allowed individuals to be members of more than one clique, it was necessary to examine all possible cliques that any one individual may have membership in and assign individuals to the clique in which they had the highest number of friendship links. To assess the strength of the friendship ties among members in each clique, friendship-cohesion was calculated as the observed number of within-clique links divided by the possible number of within-clique links (i.e., observed links $/ n_{i} \times\left[n_{i}-1\right]$. Where $n_{i}=$ the number of members in clique $i$ ) (Ennett et al., 1994; Paxton et al., 1999). A unilateral friendship nomination (i.e., A nominates B as a friend, but B does not nominate A) was counted as one within-clique link and a reciprocated friendship nomination (i.e., A nominates B as a friend, and B nominates $\mathrm{A}$ as a friend) was counted as two within-clique links. A maximum of two links was possible between any two clique members. In previous studies concerning cliques, some researchers have not calculated friendship-cohesion (e.g., Hussong, 2002), whereas others who have calculated friendship-cohesion have not set a minimum criterion cut-off score (e.g., Ennett et al., 1994). Such studies are limited in that it is unknown whether cliques consist of valid friendship relations among members. Obtaining cliques with strong friendship ties among members was of greater importance than the exhaustive assignment of participants to cliques. Therefore, as suggested by Paxton and colleagues (1999), only cliques of three or more members with 
a friendship-cohesion score of .40 or greater were included in analyses. This cut-off score was chosen arbitrarily by Paxton et al. (1999); however, they proposed that a cut-off score of .40 should be stringent enough to allow for the inclusion of cliques with valid and meaningful friendship ties between friends. Since all cliques in the present study had a friendship-cohesion score greater than .40 , all cliques were included in analyses.

Group of Friends Questionnaire. For purposes of this study, a new measure was developed to assess social behaviours, experiences, and opinions within a group of friends. This measure was administered in two forms: (a) Group of Friends Questionnaire (Friend-Report) (Appendix K) and (b) Group of Friends Questionnaire (Self-Report) (Appendix L). The measure was a compilation and modification of several measures that have previously been developed by researchers (Asher, Singleton, Tinsley, \& Hymel, 1979; Lease et al., 2002; Little, Jones, Henrich, \& Hawley, 2003; Prinstein, Boergers, \& Vernberg, 2001). These original measures were developed to assess the larger peer group context; therefore, it was necessary to modify the wording of items to apply exclusively to the friendship clique context. Both forms of the Group of Friends Questionnaire consisted of 10 subscales: (1) social dominance (2 items; adapted from Lease et al., 2002); (2) friend likeability (2 items; adapted from Asher et al., 1979); (3) prosocial behaviour - given (2 items; adapted from the Peer Experiences Questionnaire, Prinstein et al., 2001); (4) prosocial behaviour - received (2 items; adapted from the Peer Experiences Questionnaire, Prinstein et al., 2001); (5) instrumental overt aggression (2 items; adapted from Little et al., 2003); (6) instrumental relational aggression (2 items; adapted from Little et al., 2003); (7) reactive overt aggression (2 items; adapted from Little et al., 2003); (8) reactive relational aggression ( 2 items; adapted from Little et al., 
2003); (9) overt victimization ( 2 items; developed from aggression measures from Little et al., 2003); and (10) relational victimization (2 items; developed from aggression measures from Little et al., 2003). A directory of the items for each subscale of the Group of Friends Questionnaire is presented in Appendix M. Participants completed each form of the questionnaire regarding participating members of their group of friends identified in the previous measure. The Group of Friends Questionnaire (Friend-Report) required participants to rate to what extent each item described each friend in the group using a 4point Likert-scale, from 1 (Not at all) to 4 (A whole lot). The Group of Friends Questionnaire (Self-Report) required participants to rate to what extent each item described themselves when they are with their group of friends using a 4-point Likertscale, from 1 (Not at all) to 4 (A whole lot). A 4-point Likert-scale was used rather than a 5-point Likert-scale so that participants would have to decide if the items were less descriptive (i.e., choosing to respond with a " 1 " or a " 2 " on the scale) or more descriptive of themselves and each friend (i.e., choosing to respond with a " 3 " or a " 4 " on the scale). Three subscales of the Group of Friends Questionnaire (i.e., prosocial behaviour received, overt victimization, and relational victimization) were not included in analyses since the focus of the present study was to assess early adolescents' behaviour toward friends in their clique as opposed to their experiences as a result of their friends' behaviour.

To unofficially test if the questionnaires to be used in the proposed study were user-friendly, one boy in grade eight and one girl in grade seven completed the questionnaires. Both adolescents indicated that they felt comfortable completing all measures. As well, neither child had any difficulty completing the questionnaires. The 
boy completed the Group of Friends Questionnaire (Friend-Report) on five friends and finished the entire testing session in forty-five minutes. The girl completed the Group of Friends Questionnaire (Friend-Report) on seven friends and finished the entire testing session in fifty minutes. During data collection, the testing session lasted between fortyfive and sixty minutes.

A summary of each construct under investigation in the present study and the instruments used to assess each construct is outlined in Table 1. 


\section{Table 1}

Outline of the Instruments Used to Assess Each Construct

Instrument

Construct

Nominations of "most popular"

and "least popular"

Perceived Popularity

Nominations of "like most"

and "like least"

Peer Likeability and Peer Visibility

Group of Friends Questionnaire

Items \#1, 17

Social Dominance

Items \#7, 14

Friend Likeability

Items \#2, 9

Prosocial Behaviour

Items \#6, 16

Instrumental Overt Aggression

Items \#5, 18

Instrumental Relational Aggression

Items \#4, 10

Reactive Overt Aggression

Items \#8, 13

Reactive Relational Aggression

Items \#4, 5, 6, 8, 10, 13, 16, 18

Total Aggression 
Results

\section{Preliminary Analyses}

Correlational analyses were conducted between all variables of interest in the present study to determine if any significant associations existed between variables (see Table 2). For these correlations, perceived popularity was measured at the individual level. Of note, positive correlations were found between perceived popularity and peer likeability, perceived popularity and peer visibility, social dominance and peer visibility, and social dominance and all types of aggression.

Correlational analyses conducted between responses from the Group of Friends Questionnaire (Self-Report) and the Group of Friends Questionnaire (Friend-Report) indicated a lack of agreement between the two types of reporters (dominance, $r=.07, p>$ .05 ; prosocial behaviour, $r=.06, p>.05$; instrumental relational aggression, $r=.03, p>$ .05 ; instrumental overt aggression, $r=.04, p>.05$; reactive relational aggression, $r=.04$, $p>.05$; reactive overt aggression, $r=.09, p>.05$; friend likeability, $r=.09, p>.05$ ). This lack of agreement may have resulted for two reasons. First, since the Self-Report measure was the last questionnaire administered, participants may have been fatigued by the end of the session. Their fatigue was evident near the end of the administration of the questionnaire since many participants appeared to hurriedly finish the Self-Report questionnaire. Second, participants responded to the Self-Report questionnaire in an idealized manner. For example, most participants consistently rated their own use of prosocial behaviour very high (i.e., a rating of 4 on the scale from 1 through 4), and their own use of aggressive behaviour very low (i.e., a rating of 1 on the scale from 1 through 4). In contrast, idealized patterns of responses were not apparent in the Friend-Report. 
Table 2

Intercorrelations between Major Variables

\begin{tabular}{|c|c|c|c|c|c|c|c|c|c|}
\hline & 2 & 3 & 4 & 5 & 6 & 7 & 8 & 9 & 10 \\
\hline 1. Perceived Popularity & $.26^{*}$ & $.16^{*}$ & .01 & .02 & $.13^{*}$ & .03 & $.20 *$ & $.70 *$ & $.24 *$ \\
\hline 2. Social Dominance & -- & $.49 *$ & $.45^{*}$ & $.46^{*}$ & $.38^{*}$ & .03 & -.04 & .10 & $.26^{*}$ \\
\hline \multicolumn{10}{|l|}{ 3. Instrumental } \\
\hline Relational Aggression & & -- & $.65^{*}$ & $.76^{*}$ & $.57^{*}$ & $-.22 *$ & $-.27 *$ & -.04 & $.26 *$ \\
\hline \multicolumn{10}{|l|}{ 4. Instrumental } \\
\hline Overt Aggression & & & -- & $.63 *$ & $.70^{*}$ & $-.35^{*}$ & $-.32 *$ & $-.18^{*}$ & $.22 *$ \\
\hline \multicolumn{10}{|l|}{ 5. Reactive } \\
\hline Relational Aggression & & & & -- & $.61 *$ & $-.15^{*}$ & $-.26^{*}$ & $-.14 *$ & $.17 *$ \\
\hline \multicolumn{10}{|l|}{ 6. Reactive } \\
\hline Overt Aggression & & & & & - & $-.31 *$ & $-.31^{*}$ & -.07 & $.15^{*}$ \\
\hline 7. Prosocial Behaviour & & & & & & -- & $.43 *$ & $.23^{*}$ & -.06 \\
\hline 8. Friend Likeability & & & & & & & -- & $.32 *$ & .00 \\
\hline 9. Peer Likeability & & & & & & & & -- & .00 \\
\hline 10. Peer Visibility & & & & & & & & & -- \\
\hline
\end{tabular}

Note. ${ }^{*} p<.01$. 
Since the responses provided in the Self-Report version of the Group of Friends Questionnaire may have been compromised due to fatigue effects, all further analyses involving variables from the Group of Friends Questionnaire were conducted using the Friend-Report data only. Using a friend-report is beneficial because several opinions can be obtained since the friends in a clique observe and interact with a target individual in different contexts and situations. Although self-report can be an excellent source for understanding an individual's intent of their own behaviour, self-report data may be limited since it involves the opinion of only one individual. As well, some questions can be answered more easily using a friend-report. For example, one of the items for friend likeability on the self-report is "people in my group of friends like me." Although participants can rate how they believe their friends may feel, only friends can indicate their own feelings toward a target individual.

A decision was made to determine each individual's score for the subscales of the Group of Friends Questionnaire based on obtaining their average score for each subscale as opposed to obtaining their total score for each subscale. Although total scores would have provided a wider range of scores, average scores were easier to interpret as all scores were on the same metric as the Group of Friends Questionnaire. The outcome did not differ as a result of using average scores as opposed to total scores.

Correlational analyses indicated that grade was not significantly associated with any of the major variables in the present study. Previous research has indicated that grade effects are more likely to be present across the transition into secondary school (Cillessen \& Mayeux, 2004). Since participants in the present study attended middle schools composed of grades 6 through 8, grade was not included as a variable in further analyses. 
Sex differences were examined in several one-way ANOVAs. Results revealed that girls scored significantly higher than boys on peer likeability, $F(1,386)=4.40, p<.05$, social dominance, $F(1,375)=16.02, p<.001$, prosocial behaviour, $F(1,375)=88.32, p$ $<.001$, and total level of aggression, $F(1,375)=5.54, p<.05$. Means and standard deviations are presented in Table 3. Consequently, sex was included as an independent variable in subsequent analyses. The finding that girls' total level of aggression was higher than that of boys' was explored further by examining sex differences in the 4 kinds of aggression (i.e., instrumental relational aggression, instrumental overt aggression, reactive relational aggression, and reactive overt aggression) in a subsequent analysis (see pg. 51). As well, further analyses included the 4 kinds of aggression as opposed to the measure of total level of aggression since groups were expected to significantly differ in the form and function of their aggressive behaviour.

\section{Descriptive Information about Cliques}

Of the 387 participants, 11 participants ( 6 males and 5 females) were not members of a clique (i.e., they were either members of a dyad or not identified as a friend). Following the procedures outlined in the Method section, 74 cliques (comprising of 376 participants) were identified. Cliques ranged in size from 3 to 9 members $(M=5.56, S D$ $=1.62$ ). The distribution of clique size was as follows: 11 cliques were composed of 3 members, 23 cliques were composed of 4 members, 11 cliques were composed of 5 members, 16 cliques were composed of 6 members, 5 cliques were composed of 7 members, 7 cliques were composed of 8 members, and 1 clique was composed of 9 members. Thirty-four cliques were composed of all female members, 29 were all male members, and 11 were mixed sex cliques. The ratio of males to females in the mixed sex 
Table 3

Means, Standard Deviations, and Ranges for Girls and Boys on Major Variables

\begin{tabular}{|c|c|c|c|c|c|c|}
\hline \multirow[b]{2}{*}{ Variables } & \multicolumn{3}{|c|}{ Girls } & \multicolumn{3}{|c|}{ Boys } \\
\hline & $M$ & $S D$ & Range & $M$ & $S D$ & Range \\
\hline Peer Likeability ${ }^{1}$ & $.10 *$ & 1.00 & $-3.04-2.26$ & $-.11 *$ & 1.02 & $-3.36-2.35$ \\
\hline Peer Visibility ${ }^{1}$ & .00 & .99 & $-2.03-2.96$ & .00 & .99 & $-1.99-3.08$ \\
\hline Perceived Popularity ${ }^{1}$ & .00 & .98 & $-3.19-2.18$ & .00 & 1.00 & $-1.98-2.16$ \\
\hline Social Dominance $^{2}$ & $2.10 * *$ & .53 & $1.00-4.00$ & $1.88 * *$ & .53 & $1.00-4.00$ \\
\hline Prosocial Behaviour $^{2}$ & $3.22 * *$ & .53 & $1.00-4.00$ & $2.67 * *$ & .62 & $1.00-4.00$ \\
\hline Aggression (total) $^{2}$ & $1.54 *$ & .50 & $1.00-4.00$ & $1.43 *$ & .34 & $1.00-3.25$ \\
\hline Friend Likeability $^{2}$ & 3.45 & .47 & $1.50-4.00$ & 3.40 & .40 & $1.00-4.00$ \\
\hline
\end{tabular}

Note. ${ }^{1}$ indicates standardized scores; ${ }^{2}$ indicates raw scores. ${ }^{* *} p<.001 ; * p<.05$. 
cliques varied: cliques were comprised of one male and several females $(n=3)$, one female and several males $(n=2)$, or an approximately equal number of males and females $(n=6)$. Results from chi-square analyses revealed that all female cliques were most frequently comprised of 6 members $\left(\chi^{2}=26.75, p<.001\right)$, all male cliques were most frequently comprised of 4 members $\left(\chi^{2}=47.28, p<.001\right)$, and the number of members in mixed-sex cliques did not differ significantly from expected values $\left(\chi^{2}=\right.$ $9.11, p>.05)$. Friendship-cohesion scores calculated for each clique ranged between .40 and $1.00(M=.72, S D=.18)$. Since no clique fell below the minimum required friendship-cohesion score of .40 , all cliques were included in subsequent analyses. Perceived Popularity of Cliques

In an adaptation of the procedures set forth by LaFontana and Cillessen (1999), cliques were classified as: perceived popular, perceived average, or perceived unpopular by calculating the average perceived popularity of all members in a clique. It was necessary to obtain a collective score on perceived popularity for each clique in order to make comparisons between individuals in cliques of differing levels of perceived popularity. Cliques whose members' average perceived popularity score was equal to or greater than 1.00 were classified as perceived popular. Cliques whose members' average perceived popularity score equal to or less than -1.00 were classified as perceived unpopular. Most cliques whose members' average perceived popularity score was greater than -1.00 and less than 1.00 were classified as perceived average. Cliques whose members' average perceived popularity score was near either criterion cutoff score (i.e., a score between .70 and .99 or a score between -.70 and -.99 ) were re-assessed to ensure the cliques were appropriately classified since it was possible that the scores of one or 
two clique members could skew a clique's average perceived popularity score. As such, 17 of the 74 cliques were re-assessed. Since the classification of cliques based on measures of individual levels of perceived popularity has not been done in research previously, the re-assessment cut-off scores of .70 and -.70 were chosen in the present study based on the pattern of the distribution of perceived popularity scores. The distribution of the 51 perceived average cliques with perceived popularity scores between -.99 and .99 was examined at each increment of .09 . On the positive side of the scale (i.e., between 0 and .99), 13 cliques' perceived popularity scores fell between 0 and .49, no cliques' perceived popularity scores fell between .50 and .69 , and 12 cliques' perceived popularity scores fell between .70 and .99 . On the negative side of the scale (i.e., between 0 and -.99), 14 cliques' perceived popularity scores fell between 0 and $-.49,8$ cliques' perceived popularity scores fell between -.50 and -.69 , and 5 cliques' perceived popularity scores fell between -.70 and -.99 . There were no apparent gaps in the distribution of scores on the negative side of the scale; however, there was an apparent gap in the distribution of scores between .50 and .69 on the positive side of the scale. Therefore, cliques with perceived popularity scores of .70 and higher were re-assessed. To be consistent with the re-assessment criterion set for the positive side of the scale, cliques with perceived popularity scores of -.70 and lower were also re-assessed. If the majority (i.e., more than $50 \%$ of the clique) of the clique members' individual perceived popularity scores were greater than or equal to 1.00 , the clique was classified as perceived popular. If the majority of the clique members' individual perceived popularity scores were less than or equal to -1.00 , the clique was classified as perceived unpopular. None of the cliques that were re-assessed were classified as perceived average. Twelve of 
the cliques that were re-assessed were classified as perceived popular and 5 of the cliques that were re-assessed were classified as perceived unpopular.

The re-assessment technique potentially reduced the mean level of difference between the extreme groups. Nevertheless, it was important to ensure that cliques were not inappropriately classified as a result of one or two clique members with slightly outlying individual perceived popularity scores. Additionally, re-assessing the cliques allowed the sample size in the extreme groups to be increased. Prior to re-assessing the cliques, 11 cliques were classified as perceived popular, 51 cliques were classified as perceived average, and 12 cliques were classified as perceived unpopular. After reassessment, 23 cliques were classified as perceived popular, 34 cliques were classified as perceived average, and 17 cliques were classified as perceived unpopular. Every participant was thus identified as being a member of one of these three types of cliques.

\section{Dominance Rank of Individuals within Cliques}

Using the average score as rated by clique members from the social dominance subscale of the Group of Friends Questionnaire, individuals within cliques were classified as: high-dominant, average-dominant, or low-dominant. Savin-Williams and Freedman (1977) suggested that the most striking individual differences occur between the most dominant individual and the least dominant individual of a group. Therefore, only one clique member was classified as high-dominant (i.e., the individual with the highest average social dominance score as rated by his/her friends), only one clique member was classified as low-dominant (i.e., the individual with the lowest average social dominance score as rated by his/her friends), and all other clique members were classified as average-dominant. Following this procedure, 74 individuals were classified as high- 
dominant, 228 individuals were classified as average-dominant, and 74 individuals were classified as low-dominant. The mean level of social dominance for each level of dominance rank was as follows: high-dominant individuals $(M=2.56, S D=.51)$, average-dominant individuals $(M=1.98, S D=.41)$, and low-dominant individuals $(M=$ $1.50, S D=.38$ ). Although individuals who had the second highest score for social dominance in their cliques may have had scores that were close to that of the individual with the highest social dominance score, one high-dominant individual emerged in each clique. This is consistent with the ethological dominance theory that suggests there is one "alpha" member in every social group (La Freniere \& Charlesworth, 1983; Strayer \& Strayer, 1976; Strayer \& Trudel, 1984). Since it was of interest in the present study to explore extreme differences in social dominance (i.e., differences between high-dominant and low-dominant individuals) and differences across cliques (i.e., differences between high-dominant individuals across perceived popular, perceived average, and perceived unpopular cliques) a potentially wide range of scores in the average-dominant group did not affect analyses in the present study.

Association between Clique Perceived Popularity and Individual Social Dominance

The association between clique perceived popularity and individual social dominance was of particular interest to determine whether a distinction between a hierarchy based on clique perceived popularity within the peer group and a hierarchy based on individual social dominance within the clique could be delineated. Results from a bivariate correlation between clique perceived popularity and individual social dominance revealed a low positive association $(r=.16, p<.01)$, indicating that these two constructs are reasonably independent. 
Social Behaviour as a Function of Perceived Popularity and Social Dominance

It was of interest to determine if an individual's use of social behaviour within their clique varied as a function of their dominance rank within their clique and/or their clique's level of perceived popularity. To examine potential differences in social behaviour, a 2 (sex) x 3 (clique perceived popularity) x 3 (dominance rank) MANOVA was conducted, where sex (i.e., male, female), perceived popularity of clique (i.e., perceived popular, perceived average, and perceived unpopular), and dominance rank (i.e., high-dominant, average-dominant, low-dominant) were used as the independent variables, and instrumental overt aggression, instrumental relational aggression, reactive overt aggression, reactive relational aggression, and prosocial behaviour were used as the dependent variables.

Results revealed a significant main effect of sex, $F(5,354)=20.36, p<.001$. Examination of subsequent univariate analyses indicated a significant effect of sex for prosocial behaviour, $F(1,376)=58.02, p<.001$, instrumental relational aggression, $F(1$, $376)=6.68, p<.01$, and reactive relational aggression, $F(1,376)=12.94, p<.001$, whereas the results for instrumental overt aggression, $F(1,376)=.86, p>.05$, and reactive overt aggression, $F(1,376)=1.20, p>.05$, were non-significant. Females engaged in more prosocial behaviour $(M=3.22, S D=.52)$ than males $(M=2.67, S D=$ $.62)$, more instrumental relational aggression $(M=1.45, S D=.55)$ than males $(M=1.29$, $S D=.40)$, and more reactive relational aggression $(M=1.66, S D=.60)$ than males $(M=$ $1.43, S D=.39)$

Results also indicated a significant main effect of clique perceived popularity, $F(10,708)=3.46 p<.001$. Examination of subsequent univariate analyses indicated a 
significant effect of clique perceived popularity for prosocial behaviour, $F(2,376)=4.89$, $p<.01$, instrumental relational aggression, $F(2,376)=7.24, p<.001$, instrumental overt aggression, $F(2,376)=4.56, p<.05$, reactive relational aggression, $F(2,376)=3.13, p<$ .05 , and reactive overt aggression, $F(2,376)=5.55, p<.01$. Bonferroni post-hoc tests revealed that adolescents in perceived average cliques engaged in more prosocial behaviour than adolescents in perceived unpopular cliques. Adolescents in perceived popular cliques engaged in more instrumental relational aggression, instrumental overt aggression, and reactive overt aggression than adolescents in perceived average cliques. As well, adolescents in perceived unpopular cliques engaged in more instrumental overt aggression than adolescents in perceived average cliques (see Table 4).

Results also indicated a significant main effect of dominance rank, $F(10,708)=$ $3.91, p<.001$. Examination of subsequent univariate analyses indicated a significant effect of dominance rank for instrumental relational aggression, $F(2,376)=11.94, p<$ .001 , instrumental overt aggression, $F(2,376)=12.51, p<.001$, reactive relational aggression, $F(2,376)=7.11, p<.001$, and reactive overt aggression, $F(2,376)=9.14, p$ $<.001$, whereas the results for prosocial behaviour were non-significant, $F(2,376)=.90$, $p>.05$. Bonferroni post-hoc tests revealed that high-dominant individuals engaged in more instrumental relational aggression and instrumental overt aggression than all other clique members, and also engaged in more reactive relational aggression and reactive overt aggression than low-dominant individuals. Average-dominant individuals engaged in more aggression, regardless of form or function, than low-dominant individuals (see Table 5). 
Table 4

Means and Standard Deviations for Social Behaviour by Clique's Perceived Popularity

\begin{tabular}{|c|c|c|c|c|c|c|}
\hline \multirow[b]{3}{*}{ Social Behaviour } & \multicolumn{6}{|c|}{ Perceived Popularity of Cliques } \\
\hline & \multicolumn{2}{|c|}{ Popular } & \multicolumn{2}{|c|}{ Average } & \multicolumn{2}{|c|}{ Unpopular } \\
\hline & $M$ & $S D$ & $M$ & $S D$ & $M$ & $S D$ \\
\hline Prosocial Behaviour & 2.92 & .56 & $3.05^{\mathrm{a}}$ & .62 & $2.80^{\mathrm{a}}$ & .72 \\
\hline $\begin{array}{l}\text { Instrumental } \\
\text { Relational Aggression }\end{array}$ & $1.49^{\mathrm{a}}$ & .44 & $1.31^{\mathrm{a}}$ & .46 & 1.36 & .59 \\
\hline $\begin{array}{l}\text { Instrumental } \\
\text { Overt Aggression }\end{array}$ & $1.39^{\mathrm{a}}$ & .38 & $1.26^{\mathrm{ab}}$ & .36 & $1.43^{b}$ & .65 \\
\hline $\begin{array}{l}\text { Reactive } \\
\text { Relational Aggression }\end{array}$ & 1.58 & .41 & 1.51 & .56 & 1.61 & .59 \\
\hline $\begin{array}{l}\text { Reactive } \\
\text { Overt Aggression }\end{array}$ & $1.80^{\mathrm{a}}$ & .46 & $1.61^{\mathrm{a}}$ & .54 & 1.69 & .71 \\
\hline
\end{tabular}


Table 5

Means and Standard Deviations for Social Behaviour by Individual's Dominance Rank

Dominance Rank of Individuals

\begin{tabular}{|c|c|c|c|c|c|c|}
\hline \multirow[b]{2}{*}{ Social Behaviour } & \multicolumn{2}{|c|}{ High } & \multicolumn{2}{|c|}{ Average } & \multicolumn{2}{|c|}{ Low } \\
\hline & $M$ & $S D$ & $M$ & $S D$ & $M$ & $S D$ \\
\hline Prosocial Behaviour & 2.93 & .64 & 2.99 & .63 & 2.91 & .60 \\
\hline $\begin{array}{l}\text { Instrumental } \\
\text { Relational Aggression }\end{array}$ & $1.56^{\mathrm{ab}}$ & .59 & $1.38^{\mathrm{ac}}$ & .49 & $1.18^{b c}$ & .28 \\
\hline $\begin{array}{l}\text { Instrumental } \\
\text { Overt Aggression }\end{array}$ & $1.50^{\mathrm{ab}}$ & .55 & $1.33^{\mathrm{a} c}$ & .44 & $1.17^{\mathrm{bc}}$ & .27 \\
\hline $\begin{array}{l}\text { Reactive } \\
\text { Relational Aggression }\end{array}$ & $1.70^{\mathrm{a}}$ & .58 & $1.57^{b}$ & .53 & $1.36^{\mathrm{ab}}$ & .39 \\
\hline $\begin{array}{l}\text { Reactive } \\
\text { Overt Aggression }\end{array}$ & $1.82^{\mathrm{a}}$ & .59 & $1.72^{b}$ & .57 & $1.47^{\mathrm{ab}}$ & .43 \\
\hline
\end{tabular}

$\overline{\text { Note. Row means with same superscripts are significantly different from each other at } p<}$ .05 or less. 
A significant interaction between clique perceived popularity and dominance rank was not found, $F(20,1175)=1.13, p>.05$, nor were there any significant interactions involving sex (sex and clique perceived popularity, $F(10,708)=1.34, p>.05$, sex and dominance rank $F(10,708)=.97, p>.05$, sex, perceived popularity, and dominance rank, $F(20,1175)=.74, p>.05)$.

Peer Likeability, Peer Visibility, and Friend Likeability as a Function of Perceived Popularity and Social Dominance

It was of interest to determine if an individual's ratings of likeability and visibility were associated with their dominance rank and/or their clique's level of perceived popularity. To examine potential differences in likeability and visibility as rated by peers and likeability as rated by friends, a 2 (sex) x 3 (clique perceived popularity) x 3 (dominance rank) MANOVA was conducted, where sex (i.e., male, female), perceived popularity of clique (i.e., perceived popular, perceived average, and perceived unpopular) and dominance rank (i.e., high-dominant, average-dominant, low-dominant) were used as the independent variables, and scores on peer likeability, peer visibility, and friend likeability were used as the dependent variables.

A significant main effect of sex was not found, $F(3,355)=.57, p>.05$. Boys and girls were rated as equally liked by friends and peers and equally visible in the peer group.

Results indicated a significant main effect of clique perceived popularity, $F(6,710)$ $=27.71, p<.001$. Examination of subsequent univariate analyses indicated a significant effect of clique perceived popularity for peer likeability, $F(2,375)=58.50, p<.001$, peer visibility, $F(2,375)=22.78, p<.001$, and friend likeability, $F(2,375)=9.01, p<.001$. 
Bonferroni post-hoc tests revealed that adolescents in perceived popular cliques were more liked by peers than adolescents in perceived average cliques and perceived unpopular cliques. As well, adolescents in perceived average cliques were more liked by peers than adolescents in perceived unpopular cliques. In terms of peer visibility, adolescents in perceived popular cliques scored higher on peer visibility than adolescents in perceived average cliques and perceived unpopular cliques. As well, adolescents in perceived unpopular cliques scored higher on peer visibility than adolescents in perceived average cliques. In terms of friend likeability, adolescents in perceived popular cliques and perceived average cliques were more liked by friends than adolescents in perceived unpopular cliques (see Table 6).

Results also revealed a significant main effect of dominance rank, $F(6,710)=3.20$, $p<.01$. Examination of subsequent univariate analyses indicated a significant effect of dominance rank for peer visibility, $F(2,375)=4.99, p<.01$, whereas the results for peer likeability were non-significant, $F(2,375)=.20, p>.05$, and the results for friend likeability were non-significant, $F(2,375)=2.60, p>.05$. Bonferroni post-hoc tests revealed that high-dominant individuals scored higher on peer visibility than averagedominant and low-dominant individuals. Also, average-dominant individuals scored higher on peer visibility than low-dominant individuals (see Table 7).

Results also revealed a significant interaction between clique perceived popularity and dominance rank, $F(12,939)=1.85, p<.05$. Examination of subsequent univariate analyses indicated a significant effect of dominance rank for friend likeability, $F(4,375)$ $=5.19, p<.001$, whereas the results for peer likeability were non-significant, $F(4,375)=$ $1.06, p>.05$, and the results for peer visibility were also non-significant, $F(4,375)=.19$, 
Table 6

Means and Standard Deviations for Peer Likeability, Peer Visibility, and Friend

Likeability by Clique's Perceived Popularity

Perceived Popularity of Cliques

\begin{tabular}{|c|c|c|c|c|c|c|}
\hline \multirow[b]{2}{*}{ Likeability/Visibility } & \multicolumn{2}{|c|}{ Popular } & \multicolumn{2}{|c|}{ Average } & \multicolumn{2}{|c|}{ Unpopular } \\
\hline & $M$ & $S D$ & $M$ & $S D$ & $M$ & $S D$ \\
\hline Peer Likeability ${ }^{1}$ & $.53^{\mathrm{ab}}$ & .83 & $.11^{\mathrm{a} c}$ & .80 & $-.93^{b c}$ & .88 \\
\hline Peer Visibility ${ }^{1}$ & $.49^{\mathrm{a} b}$ & .91 & $-.38^{a c}$ & .83 & $.10^{b c}$ & 1.10 \\
\hline Friend Likeability $^{2}$ & $3.47^{\mathrm{a}}$ & .37 & $3.48^{b}$ & .45 & $3.23^{\mathrm{ab}}$ & .65 \\
\hline
\end{tabular}

Note. ${ }^{1}$ indicates standardized scores; ${ }^{2}$ indicates raw scores. Row means with same superscripts are significantly different from each other at $p<.05$ or less. 
Table 7

Means and Standard Deviations for Peer Likeability, Peer Visibility, and Friend Likeability by Individual's Dominance Rank

Dominance Rank of Individuals

\begin{tabular}{|c|c|c|c|c|c|c|}
\hline \multirow[b]{2}{*}{ Likeability/Visibility } & \multicolumn{2}{|c|}{ High } & \multicolumn{2}{|c|}{ Average } & \multicolumn{2}{|c|}{ Low } \\
\hline & $M$ & $S D$ & $M$ & $S D$ & $M$ & $S D$ \\
\hline Peer Likeability ${ }^{1}$ & .11 & 1.04 & .07 & .93 & -.14 & 1.01 \\
\hline Peer Visibility ${ }^{1}$ & $.27^{\mathrm{ab}}$ & 1.11 & $-.04^{a c}$ & .93 & $-.15^{b c}$ & 1.00 \\
\hline Friend Likeability $^{2}$ & 3.35 & .59 & 3.45 & .44 & 3.42 & .51 \\
\hline
\end{tabular}

Note. ${ }^{1}$ indicates standardized scores; ${ }^{2}$ indicates raw scores. Row means with same superscripts are significantly different from each other at $p<.05$ or less. 
$p>.05$. The interaction between dominance rank and friend likeability was further investigated by computing a one-way ANOVA. Results indicated that high-dominant individuals in perceived unpopular cliques were less liked by friends $(M=2.80, S D=$ $.80)$ than high-dominant individuals in perceived popular cliques $(M=3.50, S D=.31)$ and high-dominant individuals in perceived average cliques $(M=3.53, S D=.43)$.

There were no significant interactions involving sex (sex and clique perceived popularity, $F(6,710)=.40, p>.05$; sex and dominance rank $F(6,710)=.80, p>.05$; sex, perceived popularity, and dominance rank, $F(12,939)=.81, p>.05)$.

\section{Identification of Dominance Strategies}

High-dominant individuals $(n=74)$ were assigned to one of three types of dominance strategies (i.e., prosocial-dominant, aggressive-dominant, bistrategicdominant) as suggested by Hawley (1999). For purposes of this analysis, each individual's total level of aggression (i.e., their average score across the four types of aggression) was calculated to determine their overall tendency toward engaging in aggressive behaviour regardless of the form and function of aggression. High-dominant individuals were classified as prosocial-dominant if their individual score for prosocial behavior was higher than the mean of their clique and their score for total level of aggression was lower than the mean of their clique. Similarly, high-dominant individuals were classified as aggressive-dominant if their individual score for total level of aggression was higher than the mean of their clique and their individual score for prosocial behavior was lower than the mean of their clique. High-dominant individuals were classified as bistrategic-dominant if their individual scores for both prosocial behavior and total level of aggression were equal to or higher than the means of their 
clique. Following this procedure, 25 high-dominant individuals were classified as prosocial-dominant, 29 were classified as aggressive-dominant, and 20 were classified as bistrategic-dominant.

It was of interest to determine whether the type of strategy typically employed by high-dominant individuals was associated with the perceived popularity of their clique. Results from chi-square analyses indicated that the number of individuals using a particular type of dominance strategy across the three levels of clique perceived popularity did not differ from expected values, $\chi^{2}=7.41, p>.05$ (see Table 8 ). Since there were several cell-specific predictions in the present study, follow up analyses were conducted to determine whether 3 cells in particular (i.e., cell 1: prosocial dominance strategy/perceived average clique; cell 2: aggressive dominance strategy/perceived unpopular clique; cell 3: bistrategic dominance strategy/perceived popular clique) contained observed values that were significantly different than expected values. These analyses indicated that the number of individuals in perceived average cliques who used a prosocial-dominant strategy differed significantly from expected values $(z=2.2)$. The number of individuals in perceived unpopular cliques who used an aggressive-dominant strategy did not differ from expected values $(z=1.3)$. As well, the number of individuals in perceived popular cliques who used a bistrategic-dominant strategy did not differ from expected values $(z=1.6)$.

Comparison between Dominance Strategies: Social Dominance, Peer Likeability, Peer Visibility, and Friend Likeability

It was of interest to determine whether dominance strategy was associated with likeability and visibility as rated by peers as well as likeability as rated by friends in their 
Table 8

Observed and (Expected Values) for the Chi-Square Test Comparing the Number of

Prosocial-Dominant, Aggressive-Dominant, and Bistrategic-Dominant Individuals Who

Were Members of Perceived Popular, Perceived Average, and Perceived Unpopular

\section{Cliques}

Perceived Popularity of Cliques

Dominance Strategy $\quad$ Popular $(n=23) \quad$ Average $(n=34) \quad$ Unpopular $(n=17)$

Prosocial

$4(7.8)$

16 (11.5)

$5 \quad(5.7)$

Adjusted Standardized

Residual

2.2

$-.4$

Aggressive

$10 \quad(9.0)$

$10 \quad$ (13.3)

$9 \quad(6.7)$

Adjusted Standardized

Residual .5

$-1.6$

1.3

Bistrategic

$9 \quad(6.2)$

$8 \quad(9.2)$

3 (4.6)

Adjusted Standardized Residual

1.6

$-.6$

$-1.0$

Note. $\chi^{2}=7.41, p>.05$. 
clique. It was also of interest to determine whether individuals employing one of the three types of strategies were perceived as equally dominant. Initially, two MANOVAs were conducted where sex and clique perceived popularity were used as independent variables in addition to dominance strategy. Results from these analyses did not yield significant interactions with dominance strategy; thus, sex and clique perceived popularity were not used as independent variables in subsequent analyses.

The following analysis was performed to determine whether the individuals who employ one of three types of dominance strategies differed in their mean level of social dominance, peer likeability, peer visibility, and friend likeability. A series of one-way ANOVAs were conducted, where dominance strategy (i.e., prosocial-dominant, aggressive-dominant, bistrategic-dominant) served as the independent variable in each analysis, and social dominance, peer likeability, peer visibility, and friend likeability were used as the dependent variables respectively in each analysis.

The results for social dominance were non-significant, $F(2,73)=2.41, p>.05$, indicating that individuals were considered to be equally dominant, regardless of the strategy they tended to employ. Results revealed a significant effect of dominance strategy for peer likeability, $F(2,73)=7.73, p<.001$, and friend likeability, $F(2,73)=$ $7.22, p<.001$, whereas the results for peer visibility were non-significant, $F(2,73)=.54$, $p>.05$. Bonferroni post-hoc analyses indicated that prosocial-dominant individuals and bistrategic-dominant individuals were more liked by peers and more liked by friends than aggressive-dominant individuals (see Table 9). 
Table 9

Means and Standard Deviations for Social Dominance, Likeability, and Visibility by Dominance Strategy of High-Dominant Individuals

Dominance Strategy of High-Dominant Individuals

\begin{tabular}{|c|c|c|c|c|c|c|}
\hline \multirow[b]{2}{*}{ Variable } & \multicolumn{2}{|c|}{ Prosocial $(n=25)$} & \multicolumn{2}{|c|}{ Aggressive $(n=29)$} & \multicolumn{2}{|c|}{ Bistrategic $(n=20)$} \\
\hline & $M$ & $S D$ & $M$ & $S D$ & $M$ & $S D$ \\
\hline Social Dominance $^{2}$ & 2.39 & .39 & 2.70 & .58 & 2.56 & .51 \\
\hline Peer Likeability 1 & $.24^{\mathrm{a}}$ & .99 & $-.39^{a b}$ & 1.10 & $.68^{b}$ & .66 \\
\hline Peer Visibility ${ }^{1}$ & .12 & 1.04 & .43 & 1.08 & .24 & 1.24 \\
\hline Friend Likeability $^{2}$ & $3.53^{a}$ & .47 & $3.05^{a b}$ & .69 & $3.57^{b}$ & .37 \\
\hline
\end{tabular}

Note. ${ }^{1}$ indicates standardized scores; ${ }^{2}$ indicates raw scores. Row means with same superscripts are significantly different from each other at $p<.05$ or less. 


\section{Definition of Popularity}

It was of interest in the present study to obtain a definition of perceived popularity as it was understood by the early adolescents in this sample. Similar to the procedures outlined by LaFontana and Cillessen (2002), each word participants used to describe what it means to be popular was assigned to a category. The 10 categories used by LaFontana and Cillessen (2002) (i.e., attractiveness, intelligence, competencies, athleticism, deviance, likeability, connectedness, dominance, prosocial behaviour, and antisocial behaviour) were followed as a guide in developing 12 categories for the present study. A total of 1343 words were coded by a graduate student researcher. Each word was coded for the category and, when applicable, the subcategory to which it belonged. For example, the word "pretty" was coded as 1a, where 1 = category (Attractiveness), and $\mathrm{a}=$ subcategory (Pretty/Handsome/"Hot"). A second graduate student researcher coded words from a random sampling of 75 questionnaires (approximately $20 \%$ of the participants) to determine the reliability of initial coding. Cohen's kappa was .88 for the pair of coders across categories. Any discrepancies in coding were resolved through discussion and mutual agreement. The word most frequently reported to describe what it means to be popular was "cool" ( $n=199 ; 51.4 \%$ of the participants used this word). Aside from "cool," participants tended to describe popularity in terms of Attractiveness, Connectedness, and Negative Behaviour/Attitude. Frequencies of words, arranged by categories and subcategories, are presented in Table 10. 
Table 10

Frequencies of Words Used to Describe What it Means to be Popular

Popularity Descriptions

Number of Words

Category

Subcategory

"Cool"

199

Attractiveness

275

Pretty/Handsome/“Hot”

Nice Clothes/Hair/Make-up

92

Skinny

Clean

Connectedness

In a Group/Has Lots of Friends

Known

Fun/Want to Be Around Them

Goes to Parties

Has a Boyfriend/Girlfriend

Negative Behavior/Attitude

179

Snobby/Snotty/Conceited

80

Mean

58

Rude

30

Athletic/Jock

90 
Table 10 Continued

Frequencies of Words Used to Describe Popularity

Popularity Descriptions

Number of Words

Category

Subcategory

Prosocial Behavior

89

Nice

Friendly

Honest/Trustworthy

8

Rich/Has Lots of Stuff

76

Funny/Witty

58

Smart

54

Liked

42

Dominance/Power

Rebel/Showoff

23 


\section{Discussion}

Previous developmental researchers have focused on quantitative investigations of the associations between social status and social behaviour used toward peers, not differentiating between behaviour targeted at a friend versus a non-friend. Comparatively, some sociologists have conducted ethnographic studies that examined the role of social status in the behaviours used specifically within friendship cliques. A small number of studies have quantitatively assessed the relationship between social status and aggression used within dyadic friendships (e.g., Koop \& Hawley, 2004); however, the present study was the first to quantitatively examine the function of social status as it relates to social behaviour used within friendship cliques.

A major goal of the present study was to determine whether a status hierarchy existed between cliques within the larger peer group (based on the collective perceived popularity of the individuals who comprise each clique) and between individuals within each clique (based on the social dominance of each individual member within their clique). Delineating these two types of hierarchies may provide a useful template from which researchers can conceptualize the social structure of early adolescents within the larger peer group and within friendship cliques. Significant differences in outcome between each level of social status (i.e., between perceived popular, perceived average, and perceived unpopular; between high-dominant, average-dominant, and low dominant) support the hypothesis that these two types of hierarchies are indeed present in the early adolescent peer group. The results from this study suggest that social status is associated with how one is perceived by friends and peers and also is associated with one's behaviour within the clique. 


\section{Profile of Individuals in Perceived Popular Cliques}

As predicted, individuals in perceived popular cliques were found to be more aggressive toward the friends in their clique than those in perceived average cliques. Of the three levels of clique perceived popularity, those in perceived popular cliques used the most instrumental relational aggression. Some researchers have theorized that this type of aggression is used intentionally to damage another peer's social reputation thereby maintaining their own high status (e.g., Prinstein \& Cillessen, 2003). Therefore, those in perceived popular cliques may use instrumental relational aggression toward their friends to secure their own position in the clique. In turn, they could potentially exile another member from the clique or at least facilitate a decrease in their friend's social position within the clique.

In terms of prosocial behaviour, individuals in perceived popular cliques did not behave more prosocially toward the friends in their clique than individuals in other cliques. This finding partially supports the hypothesis that individuals in perceived popular cliques would use similar levels of prosocial behaviour as individuals in perceived average cliques yet higher levels than those in perceived unpopular cliques. Previous research has suggested that perceived popular individuals often use high levels of prosocial behaviour to balance their use of aggressive behaviour (Prinstein, 2001); therefore, it is surprising that perceived popular clique members in the present study did not use more prosocial behaviour than perceived unpopular clique members. However, it is possible that early adolescents may be willing to sacrifice a highly prosocial, nonaggressive friendship in order to have membership in a perceived popular clique (Merten, 2004). Contrary to what was expected, individuals in perceived popular cliques were well 
liked by their friends at levels similar to those in perceived average cliques. Given the fact that individuals in perceived popular cliques were prosocial toward their friends, it is possible that this prosocial behaviour provided sufficient incentive to maintain amiable friendships, since, for the entire sample, prosocial behaviour was highly correlated with friend likeability.

As anticipated, individuals in perceived popular cliques scored the highest on peer visibility. These individuals are highly prominent in the social milieu, allowing for their peers to form strong opinions of them. As well, individuals in perceived popular cliques were found to be more liked by peers than individuals in perceived average and perceived unpopular cliques. Although many peers may personally like those in perceived popular cliques, these positive feelings are potentially an indication of admiration, since those with high social status are looked up to and most often emulated by others (Heilman, 1998; Lease, Kennedy, et al., 2002; Lease, Musgrove, et al., 2002). Despite the use of aggression within their friendship cliques and even though they are described as "mean," "rude," and "conceited" by peers, perceived popular early adolescents seem to be held in high esteem and may be glorified.

\section{Profile of Individuals in Perceived Average Cliques}

As hypothesized, results indicated that individuals in perceived average cliques were the least aggressive toward the friends in their clique when compared to individuals in perceived popular and perceived unpopular cliques. Researchers have suggested that members of perceived average cliques engage in less aggression of all forms within their cliques because they are not concerned with the need to attain a high social status (Adler \& Adler, 1998). In other words, within perceived average cliques, there may be less 
competition to achieve or maintain a high dominance rank; consequently, less aggressive behaviour is used.

As expected, results revealed that individuals in perceived average cliques engaged in more prosocial behaviour toward the friends in their cliques than those in perceived unpopular cliques. Since perceived average clique members scored low on aggression and high on prosocial behaviour, it was not surprising to discover that they were well liked by friends. Partial support was found for the hypothesis that perceived average clique members would be more liked by friends than perceived popular and perceived unpopular clique members. Previous researchers have described members of perceived average cliques as having highly intimate, stable and satisfying friendships. These individuals tend to be loyal and trustworthy friends who often utilize prosocial resolution strategies when in conflict with friends in their clique (Adler, \& Adler, 1998).

Although rated as less liked by peers than individuals in perceived popular cliques, individuals in perceived average cliques were more liked by peers than those in perceived unpopular cliques. Therefore, partial support was found for the hypothesis that individuals in perceived average cliques would be well liked by peers. Cillessen \& Mayeux (2004) have found empirical evidence to suggest that, over time, perceived popular individuals become less liked by peers. Perhaps, as the peer likeability of perceived popular individuals decreases, the peer likeability of perceived average individuals may increase, especially since early adolescents in perceived average cliques are less likely to exclude anyone from their recreational activities and tend to be amiable toward many peers (Adler \& Adler, 1998). Results also revealed that individuals in perceived average cliques scored the lowest on peer visibility. Adler and Adler (1998) 
have suggested that members of these cliques may be aware of, and satisfied with, their mid-level status. They may not be willing to sacrifice their close friendship ties for higher status. Furthermore, they may not desire or deem it necessary to be the centre of attention nor do they require peer recognition to validate their status within the peer hierarchy.

\section{Profile of Individuals in Perceived Unpopular Cliques}

Results indicated that individuals in perceived unpopular cliques used more instrumental overt aggression toward the friends in their clique than did individuals in perceived average cliques. Adler and Adler (1998) have found ethnographic evidence to suggest that these individuals are often discontented with their social position in the peer group. If this is the case, the findings of the present study may reflect their desire to increase their status; however, instrumental overt aggression may not prove as effective a method as using instrumental relational aggression (Prinstein \& Cillessen, 2003). Furthermore, as hypothesized, individuals in perceived unpopular cliques were less prosocial toward the friends in their clique than individuals in perceived average cliques. Those in perceived unpopular cliques may not exercise the prosocial skills necessary to counterbalance the negative effects of their aggression; therefore, they remain at the bottom of the peer status hierarchy. Contrary to the individuals in perceived popular cliques who often successfully achieve their goals using instrumental aggression (Prinstein \& Cillessen, 2003), individuals in perceived unpopular cliques may not possess the savoir-faire required to produce their desired effect (Adler \& Adler, 1998).

Similar to the study by Kosir and Pecjak (2005) which was conducted at the peer group level, results from the present study indicated that individuals in perceived unpopular cliques were the least liked by peers. It is possible they do not fit in with the 
rest of the peer group because they tend to deviate from the norm in terms of their appearance and behaviour (Adler \& Adler, 1998; Lease, Musgrove, et. al., 2002). Furthermore, in the present study, perceived popular clique members scored high on peer visibility, due to many "like least" nominations since they received few "like most" nominations. Additionally, when compared to those in perceived popular and perceived average cliques, these individuals were least liked by friends. This may occur due to the higher levels of aggression and lower levels of prosocial behaviour used within their cliques. Although perceived unpopular cliques consisted of reciprocated friendships, Adler and Adler (1998) suggest they may be forced relationships based on availability since these individuals tend to be excluded by the larger peer group. Perhaps individuals in perceived unpopular cliques do not have strong positive feelings for one another because their affiliation is due to a lack of an alternative source of friendship. Profile of High-Dominant Individuals

As predicted, high-dominant individuals within cliques of all levels of perceived popularity were the most aggressive members of their clique. Particularly, these individuals used more instrumental aggression (both relational and overt forms) toward the friends in their clique than any subordinate members. Previous research has shown that instrumental aggression is often used by high-dominant individuals to protect their position within the peer group (Hawley, 2003b; Hawley et al., 2002; Strayer \& Strayer, 1976). Results of the present study indicated that instrumental aggression may be a useful tool in defending one's high dominant position within their friendship clique as well.

In addition, high-dominant individuals, regardless of the perceived popularity of their clique, scored higher on peer visibility than those who were of lower relative 
dominance rank. This finding indicated that these high-dominant individuals, who were prominent within their clique, were also salient within the larger peer group. Highdominant individuals may interact with their friends in a manner that is readily apparent to the entire peer group. Alternatively, these individuals may utilize dominance strategies within the larger peer group in addition to within their clique, thereby increasing their visibility. Therefore, as anticipated, it appears that social dominance may be a distinct construct that is not necessarily dependent on perceived popularity (Lease, Kennedy, et al., 2002); especially since results revealed that the correlation between these two constructs was low.

Profiles of Average-Dominant and Low-Dominant Individuals

Among cliques of all levels of perceived popularity, average-dominant individuals tended to use moderate levels of aggression within their clique. Not surprisingly, they were less aggressive than those who were high-dominant but were more aggressive than those who were low-dominant. As well, average-dominant individuals had moderate levels of peer visibility, scoring lower than high-dominant individuals but higher than low-dominant individuals.

Low-dominant individuals, regardless of their clique's perceived popularity, were the least aggressive members of their clique. Particularly, they used very little instrumental aggression. Following the suggestion of Savin-Willams (1979; SavinWilliams \& Freedman, 1977) it was hypothesized in the present study that low-dominant individuals in all cliques would be least liked by friends. Contrary to what was expected, low-dominant individuals were reasonably well liked by friends, possibly due to the fact that they used little aggression and were moderately prosocial. Compared to the rest of 
their clique, low-dominant individuals scored the lowest on peer visibility. Perhaps because these individuals are likely to be non-aggressive within their clique as well as within the larger peer group (Lease, Kennedy, et al., 2002), and tend to be withdrawn (Lease, Kennedy, et al., 2002; Savin-Willams, 1979; Savin-Williams \& Freedman, 1977) yet get along with others, they go somewhat unnoticed by the larger peer group. Strategies used by High-Dominant Individuals: Prosocial, Aggressive, and Bistrategic In keeping with the previous research conducted by Hawley (2003a, 2003b; Hawley et al., 2002), it was hypothesized that high-dominant individuals in perceived average cliques would be mainly prosocial-dominant, high-dominant individuals in perceived popular cliques would be primarily bistrategic-dominant, and high-dominant individuals in perceived unpopular cliques would be mostly aggressive-dominant. Although analyses did not yield significant results, the pattern of results appeared to be in the predicted direction. For example, high-dominant perceived average clique members may most often use prosocial-dominant strategies.

Interestingly, the prosocial-dominant, aggressive-dominant, and bistrategicdominant individuals were perceived by their friends to be equally dominant among cliques across all levels of perceived popularity. In other words, the type of strategy used by high-dominant individuals did not influence their cliques' perception of the degree of their social dominance. This finding indicates that all three strategies can be effective in maintaining the highest dominance rank within a clique. However, since few highdominant individuals in perceived popular cliques used a prosocial-dominant strategy, this indicates that in these cliques, a certain level of aggression may be necessary to maintain dominance. As well, some aggression may be acceptable or tolerated in certain 
perceived average cliques, although those who use a prosocial-dominant strategy may find the most success (Hawley, 2002).

As expected, regardless of the perceived popularity of their clique, high-dominant individuals who employed either a prosocial-dominant or bistrategic-dominant strategy were more liked by peers and friends than those who used an aggressive-dominant strategy. Similarly, previous research has shown that high-dominant individuals employing these strategies at the peer group level were well liked by peers and were highly sought after as friends (Koop \& Hawley, 2004). These findings, in addition to the results of the present study, suggest that high-dominant individuals who primarily engage in prosocial behaviour may be well liked, regardless of whether they also engage in aggressive behaviour.

Lack of Interaction Effects between Clique Perceived Popularity and Dominance Rank

Several interaction effects were hypothesized in regards to early adolescents' social behaviour within cliques. It was expected that individuals would behave differently according to their dominance rank in addition to the perceived popularity of their clique. These hypotheses were: high-dominant individuals in perceived popular cliques would use more prosocial behaviour than high-dominant individuals in perceived unpopular cliques; high-dominant individuals in perceived average cliques would use more prosocial behaviour than high-dominant individuals in perceived popular and perceived unpopular cliques; high-dominant individuals in perceived unpopular cliques would use more instrumental overt aggression than high-dominant individuals in perceived popular and perceived average cliques; and low-dominant individuals in perceived unpopular cliques would use more reactive overt aggression than low-dominant individuals in 
perceived popular and perceived average cliques. None of these hypotheses were supported. High-dominant individuals did not differ in behaviour across cliques of all levels of perceived popularity; neither did average-dominant nor low-dominant individuals. This suggests that a dominance hierarchy within cliques may be independent of the status hierarchy within the larger peer group.

\section{Sex Differences}

Few sex differences emerged in the present study. Across all levels of social status, girls were more prosocial toward the friends in their clique than were boys. This is consistent with previous research which has suggested that girls are highly prosocial toward peers (Hawley, 2003b; Lease, Kennedy, et al., 2002). As well, girls were somewhat more liked by peers than were boys, a finding that could be a result of girls' higher levels of prosocial behaviour. Alternatively, this finding may be due to the fact that some boys may have misunderstood the peer likeability instrument, perceiving it to assess romantic liking. During separate data collection sessions, a few boys asked the survey administrator if the peer likeability instrument was assessing who they liked the most "as a friend or more than a friend." By happenstance, such questions were raised in the sessions that were held later in the data collection process. Therefore, some boys in earlier sessions who did not receive clarification of the true intention of the item may have been reluctant to nominate other boys as individuals whom they liked.

Overall, girls were also more aggressive toward the friends in their clique than boys; however, this difference was due to the fact that girls were more relationally aggressive than boys, yet they did not differ from boys in terms of overt aggression, a 
finding that is consistent with previous research conducted at the peer group level (e.g., Prinstein \& Cillessen, 2003).

The most interesting sex difference was that girls were found to be more socially dominant than boys. Although not directly compared, the mean levels of social dominance reported by Lease, Kennedy, et al. (2002) suggested that both perceived popular girls and average girls may be more socially dominant among all peers (i.e., not only within friendship cliques) than perceived popular boys and average boys. These results support the findings in the present study. Since girls may be particularly concerned with social status and wielding their social dominance over others (Heilman, 1998; Merten, 1997, 2004), it is possible that girls may use high levels of controlling behaviours to preserve their intimate, intense, and exclusive friendships (Grotpeter \& Crick, 1996) and also to preserve their own social standing within their clique.

Beyond these overall mean differences, sex did not affect the associations between social status (i.e., the clique's perceived popularity and the individual's dominance rank) and social behaviour within cliques or peer and friend preferences. Thus, it appears that the relationship between social status and aggressive and prosocial behaivour within cliques, and the relationship between social status and peer likeability, peer visibility, and friend likeability is the same for boys and girls. For example, high-dominant boys and girls used similar levels of aggression toward the friends in their clique, and boys and girls in perceived popular cliques reported similar levels of friend likeability. These findings indicate that, when early adolescents are grouped based on their social status, certain outcomes such as within-clique behaviour may be similar for boys and girls. 


\section{What Does it Mean to be Popular?}

Popularity, as understood by the early adolescents in this study, was most often described in terms of "coolness." More than half of the sample used the word "cool" to describe what it means to be popular. The idea that perceived popular individuals are “cool” has been reported in ethnographic studies (Adler \& Adler, 1998) as well as empirical studies (Farmer et al., 2003; Lease, Musgrove et al., 2002; Rodkin et al., 2000). Since the aforementioned empirical studies assessed "coolness" by obtaining nominations of who is "cool - just about everybody in school knows this person," these researchers implied that "coolness" is determined by how well known an individual is. By utilizing an open-ended question to define popularity in the present study, this method did not suggest or in any way lead participants in the definitions they provided. Using this approach, results from the present study validated the notion that early adolescents believe perceived popular individuals are indeed "cool."

Participants in the present study indicated that a major aspect of being popular was physical attractiveness. Since physical attractiveness is a highly valued characteristic (Feingold, 1992), it is not surprising that these individuals are often afforded high status. Physical attractiveness has been found to predict several positive outcomes such as having more dates and more friends (Feingold, 1992), and receiving more attention from peers (La Freniere \& Charlesworth, 1983). In addition to the present study, several previous studies have found that perceived popular individuals are identified by peers as being highly attractive (LaFontana and Cillessen, 2002; Lease, Kennedy, et al., 2002); therefore, attractiveness appears to be associated with high social status. 
Similar to LaFontana and Cillessen (2002), results from the present study indicated that popularity was also defined in terms of connectedness, particularly as having a large network of friends. Adler and Adler (1998) noted that often times several perceived popular cliques associated with one another, thereby providing them with a very large social network. Thus, perceived popular individuals may be reputed as having many friends because they often socialize with individuals in other perceived popular cliques, all of whom are part of the larger "popular crowd" (Prinstein, 2001).

Participants in the present study noted that engaging in negative behaviour and having a negative attitude was a key component of being popular. Words such as "snobby," "mean," and "rude" were used to portray the conduct of these individuals. Comparatively, popularity was less often describe as being "nice" and "friendly." Previous ethnographic research has found that perceived popular children and adolescents are frequently described in a negative manner (Adler \& Adler, 1998; Eder, 1985; Eder et al., 1995; Merten, 1997). It is possible that many perceived popular early adolescents choose to flaunt their popularity and use their social power in more negative ways (LaFontana \& Cillessen, 2002) as opposed to being humble about their high status. Perhaps being "snobby," "mean," and "rude" is an effective strategy for defending a high social position because those of lower status may feel intimidated by such displays of social power. Alternatively, negative behaviour may be more noticeable than prosocial behaviour (Xie, Cairns, \& Cairns, 1999); thus, it could be regarded as a comparatively more salient trait of those who are perceived as popular.

Popularity was described by almost one quarter of the participants in terms of athleticism or being a "jock," a finding that is consistent with numerous other studies of 
perceived popularity (Eder et al., 1995; Farmer et al., 2003; LaFontana \& Cillessen, 2002; Lease, Kennedy, et al., 2002; Rodkin et al., 2000). Athleticism may be an important component to popularity since athletic activities are regarded as highly visible and prestigious (Eder et al., 1995). In addition, 20\% of the participants used the word "rich" to describe what it means to be popular. Similarly, previous research has revealed a positive correlation between being perceived as powerful and being perceived as wealthy (Vaillancourt, Hymel, \& McDougall, 2003). As such, perceived popular individuals may possess more spending power (i.e., have expensive possessions, clothes, and money to spend) than their peers (Lease, Kennedy, et al., 2002) and tend to enjoy expensive hobbies (Adler \& Adler, 1998).

It is important to note that, although popularity was described in a manner similar to other studies, this study utilized an open-ended question to assess what it means to be popular; whereas all previous empirical studies (see LaFontana \& Cillessen, 2002 for an exception) asked participants to nominate peers who best suited characteristics that the researchers believed would conceptually be related to perceived popularity. The method used in the present study provided further support for previous findings but also uncovered descriptions of popularity not previously reported such as "funny/witty" and "rebel/showoff." These descriptions indicate that perceived popular early adolescents may try to draw attention to themselves, possibly to increase their visibility within the peer group. Such behaviour could be highly entertaining to others; thus, perceived popular individuals may have charismatic personalities that their peers find appealing. It appears that early adolescents' conceptualization of popularity is more synonymous with "coolness" or social prominence than being well liked. Only $11 \%$ of 
the sample indicated that being popular meant being well liked. In fact, out of the 1343 words used to describe what it means to be popular, only $3 \%$ indicated some variation of the word "liked." Paradoxically, the correlation between perceived popularity and peer likeability was highly positive. Among previous quantitative studies using early adolescent samples, correlations between perceived popularity and peer likeability have varied. Some researchers have found the correlation to be low (e.g., Kosir \& Pecjak, 2005; Parkhurst \& Hopmeyer, 1998; Rose, Swenson, et al., 2003), others moderate (e.g., Hawley, 2003b), while even others found a marked degree of correlation (e.g., Cillessen \& Mayeux, 2004; LaFontana \& Cillessen, 2002). Both the present study and the study by LaFontana and Cillessen (2002) found a marked degree of correlation (i.e., $r=.70$ for both studies) between perceived popularity and peer likeability; however, both studies found that likeability was not highly related to perceived popularity by qualitative (i.e., descriptive) methods. Through individual interviews with children and early adolescents, LaFontana and Cillessen (2002) found that perceived popular same-sex peers were seldom described as well liked. Perhaps perceived popular individuals are sometimes rated high on quantitative measures of peer likeability because they are highly admired (Lease, Kennedy, et al., 2002) not necessarily because they are liked per se. As well, results from the present study suggested that constructs other than likeability (e.g., being "cool," attractive, and connected) may be more salient and necessary to defining what it means to be popular. Therefore, if their aim is to study popularity as it is understood by participants, researchers should assess perceived popularity rather than sociometric popularity (i.e., likeability). 


\section{Limitations and Future Directions}

There were a few limiting factors in the present study. Although every effort was made to achieve a high participation rate, a $100 \%$ participation rate was not obtained. Thus, there may have been a few members of each clique who were not accounted for. As a result, it is possible that the dominance hierarchy within each clique may have been slightly different had every student in each school participated in the study. However, a dominance hierarchy was found to exist regardless of who held each position within the clique at the time of data collection.

In the lexicon of the participants in this study, the term "cool" appeared to be fairly synonymous with being perceived as popular. This word was used by over half of the sample but it remains to be defined by early adolescents themselves. Previous researchers operationally defined "cool” as being well known (Farmer et al., 2003; Lease, Musgrove et al., 2002; Rodkin et al., 2000); however early adolescents' conception of the term "cool" may be different from that of researchers. Therefore, a further study to clarify the definition of "cool" would explain whether these researchers' understanding of "coolness" is similar to participants. Since, in the present study, being popular was described in terms of being "cool" more often than it was described as being well known, early adolescents may believe that "coolness" and popularity are one in the same.

As previously mentioned, researchers have proposed that individuals engage in prosocial behaviour for altruistic (i.e., selfless) or egoistic (i.e., selfish) purposes (Eisenberg \& Mussen, 1989; Trivers, 1971). Hawley (2003a, 2003b) applied such a notion in her research on social dominance; however, only egoistic prosocial behaviour was measured. To obtain a broader understanding of participants' intended function of 
their prosocial behaviour, future studies should assess both altruistic and egoistic tendencies in the investigations. This will also allow researchers to determine if social dominance or perceived popularity is associated with the function of an individuals' use of prosocial behaviour.

The present study assessed the extent to which within-clique aggressive behaviour was characteristic of early adolescents. What remains unknown is the frequency of aggressive behaviour used among friends in cliques. Individuals may be regarded as aggressive because it often is a noticeable behaviour, or because they frequently act aggressively, or perhaps it is a combination of the two. It would be expected that the frequency of aggressive acts would be fairly low since it is unlikely that friends would tolerate constant hostility within their friendships. Nevertheless, even occasional acts of aggression from friends in one's clique are liable to be hurtful to victims, especially since the aggression originates from an individual with whom the victim shares a close relationship.

Efforts were not made to compare all female cliques, all male cliques, and mixedsex cliques since the primary focus of the present study was not to examine sex differences. Nevertheless, future studies would benefit from undertaking such a comparison. It would be interesting to determine whether boys or girls are primarily the most dominant member in mixed-sex cliques. As well, it would be of interest to determine whether the level of within-clique aggression is higher in one type of clique than the others. Such studies would allow researchers to better understand the dynamics within boys' and girls' friendship cliques. 
The "Group of Friends Questionnaire" was developed using theoretical factors that were designed to address the research questions of the present study. Since the focus of the present study was conceptually based, it was not of interest to assess the psychometric properties of this newly developed instrument. Future studies should include a principal components factor analysis as well as tests of reliability and validity to determine whether this measure is psychometrically sound.

\section{Conclusions}

Results from the present study suggested that membership in a perceived popular clique may be associated with drawbacks as well as benefits. The finding that perceived popular clique members were aggressive toward the friends in their clique contributes to the mounting evidence that there are negative components to being perceived as popular. However, the findings from the present study suggested that, despite the existence of aggression within their cliques, members of perceived popular cliques were prosocial toward their friends and well liked by friends and peers. Perhaps, perceived popular clique members maintain a relationship with one another because the benefits associated with membership in these cliques may outweigh any negative aspects.

Many researchers have neglected studying those who are average; rather, they have often focused on those who are at extreme ends of a spectrum or have used an average group only as a means of comparison. This study has demonstrated the importance of devoting attention to an average group, especially when examining perceived popularity. Membership in a perceived average clique may be highly beneficial as it may foster a positive environment for early adolescents. Results from the present study suggested that individuals in perceived average cliques were reasonably liked by their peers, were well- 
liked by their friends, and engaged in high levels of prosocial acts as well as low levels of aggressive behaviour within their friendship cliques. This study provided further support for Adler and Adler's (1998) finding that individuals in "middle friendship circles" may have the healthiest relationships with their friends.

Membership in perceived unpopular cliques may be associated with the fewest positive aspects. Individuals in these cliques were aggressive toward their friends and, compared to individuals in perceived popular and perceived average cliques, were least liked, not only by their peers, but also by their friends. It is possible that their use of aggression may contribute to their lower levels of likeability.

In terms of social dominance within friendship cliques, it appears that the higher one's dominance rank, the more aggressive toward friends one may be. In many cliques, a certain degree of aggression may be necessary to maintain a high-dominant position. Additionally, results from the present study indicated that high-dominant individuals were regarded as highly visible by the entire peer group regardless of the perceived popularity of their clique. Previous researchers have assumed that social dominance and perceived popularity are synonymous constructs (e.g., Parkhurst \& Hopmeyer, 1998; Prinstein, 2001). However, the findings of the present study reinforced the suggestion by Lease, Kennedy, et al. (2002) that perceived popularity and social dominance should be treated as separate constructs.

High-dominant individuals were perceived as equally socially dominant within their clique regardless of the strategy they tended to employ. In other words, prosocialdominant, aggressive-dominant, and bistrategic-dominant individuals all may find success in exerting their power and influence over the friends in their clique. Despite the 
effectiveness of their choice of dominance strategy, these three types of high-dominant individuals are differentially liked by peers and by friends. Prosocial-dominant and bistrategic-dominant individuals were most liked within the peer group as well as within their friendship cliques. It appears that high-dominant individuals, who are primarily prosocial toward the friends in their clique, even if they also use a high level of aggressive behavior, are more liked than high-dominant individuals who use aggressive strategies alone.

In sum, the findings from the present study were important for several reasons. First, applying what was known from previous qualitative research, the present study showed that two distinct hierarchies can be distinguished among early adolescent peer groups: a dominance hierarchy within cliques based on measures of individual social dominance, and a status hierarchy within the larger peer group, based on measures of clique perceived popularity. Delineating this structure provides a useful template from which researchers can understand how early adolescents may be organized socially. Also, the present study was the first to explicitly ask participants to define what it means to be popular. Participants' responses provided insight into early adolescents' understanding of popularity and indicated that they typically do not define popularity in terms of being well liked, which is the traditional definition used by developmental psychologists. Additionally, the present study showed that aggression can be measured within friendship cliques. Aggressive behaviour toward friends may be accompanied by social reinforcement within the clique, since a high dominance rank was afforded to the individuals who were most aggressive toward their friends. Aggression used toward friends may also be accompanied by social reinforcement within the larger peer group. 
For example, members of perceived popular cliques were afforded high status in the peer hierarchy, were well liked by friends and peers, and yet were aggressive toward the friends in their clique. In addition, high-dominant individuals who were bistrategicdominant, utilizing high levels of both prosocial and aggressive strategies, were well liked by friends and peers, suggesting that aggression may be tolerated, and perhaps rewarded, especially when it is accompanied by prosocial behaviour.

These findings have important implications, suggesting that parents, educators, and professionals should be made aware that aggression does not always originate from a non-friend, and aggressive behaviour is not exclusively associated with low social status, both of which have been common misconceptions. Anti-bullying programs would be more effective with the inclusion of such information. A general intervention or prevention program targeted toward all children might not be the most effective approach. Programs should be designed to target children's specific requirements. For example, programs aimed at high status children should include empathy training. These individuals would benefit from the knowledge that it is not acceptable behaviour to attain one's goals by hurting others. Providing social skills training to these highly sociable children would be redundant. Also of great importance would be to ensure children are taught that enduring aggressive behaviour that originates from anyone, including one's friends, should never be acceptable. Many previous studies indicated that friendship acts as a protective buffer against victimization (e.g., Bollmer, Milich, Harris, \& Maras, 2005); however, friendship may not protect one from victimization if the aggression originates within the friendship clique. Overall, the results from the present study offer a 
more comprehensive understanding of the complex association between social status and the dynamics within early adolescent friendship cliques. 


\section{References}

Adler, P. A., \& Adler, P. (1998). Peer power: Preadolescent culture and identity. New Brunswick, NJ: Rutgers University Press.

Alexander, R. D. (1977). Natural selection and the analysis of human sociality. The Changing Scenes in Natural Science, 12, 283-337.

Asher, S. R., Singleton, L., Tinsley, B. R., \& Hymel, S. (1979). A reliable sociometric measure for preschool children. Developmental Psychology, 15, 443-444.

Atlas, R. S., \& Pepler, D. J. (1998). Observations of bullying in the classroom. Journal of Educational Research, 92(2), 86-99.

Bandura, A. (1973). Psychological mechanisms of aggression. In R. G. Geen, \& E. I. Donnerstein (Eds.), Aggression: Theoretical and empirical reviews (Vol. 1, pp., 140). New York: Academic Press.

Bjorkqvist, K., Lagerspetz, K. M. J., \& Kaukiainen, A. (1992). Do girls manipulate and boys fight? Developmental trends in regard to direct and indirect aggression. Aggressive Behavior, 18, 117-127.

Block, J. H. (1983). Differential premises arising from differential socialization of the sexes: Some conjectures. Child Development, 54, 1335-1354.

Bollmer, J. M., Milich, R., Harris, M. J., \& Maras, M. A. (2005). A friend in need: The role of friendship quality as a protective factor in peer victimization and bullying. Journal of Interpersonal Violence, 20(6), 701-712.

Borgatti, S. P., Everett, M. G. and Freeman, L. C. (2002). Ucinet for Windows: Software for Social Network Analysis. Harvard, MA: Analytic Technologies.

Bukowski, W. M., \& Hoza, B. (1989). Popularity and friendship: Issues in theory, 
measurement, and outcome. In T. J. Berndt \& G. W. Ladd (Eds.), Peer relationships in child development, (pp. 15-45). New York: Wiley \& Sons.

Bukowski, W. M., Sippola, L., Hoza, B., \& Newcomb, A. F. (2000). Pages from a sociometric notebook: An analysis of nomination and rating scale measures of acceptance, rejection, and social preference. In W. Damon (Series Ed.) and A. H. N. Cillessen \& W. M. Bukowski (Vol. Eds.), New directions for child and adolescent development: No. 88. Recent advances in the measurement of acceptance and rejection in the peer system (pp. 11-26). San Francisco, CA: Jossey-Bass.

Bukowski, W. M., Sippola, L., \& Newcomb, A. F. (2000). Variations in patterns of attraction of same- and other-sex peers during early adolescence. Developmental Psychology, 36, 147-154.

Cairns, R. B., Perrin, J. B., \& Cairns, B. D. (1985). Social structure and social cognition in early adolescence: Affiliative patterns. Journal of Early Adolescence, 5(3), 339355.

Cillessen, A. H. N., Jiang, X. L., West, T. V., \& Laszkowski, D. K. (2005). Predictors of dyadic friendship quality in adolescence. International Journal of Behavioral Development, 29, 146-155.

Cillessen, A. H. N., \& Mayeux, L. (2004). From censure to reinforcement: Developmental changes in the association between aggression and social status. Child Development, 75(1), 147-163.

Coie, J. D., \& Dodge, K. A., (1983). Continuities and changes in children's social status: A five-year longitudinal study. Merrill-Palmer Quarterly, 29, 261-282.

Coie, J. D., \& Dodge, K. A., (1988). Multiple sources of data on social behavior and 
social status. Child Development, 59, 815-829.

Coie, J. D., \& Dodge, K. A., (1998). Aggression and antisocial behavior. In W. Damon (Series Ed.) \& N. Eisenberg (Vol. Ed.), Handbook of child psychology: Vol. 3 Social, emotional, and personality development ( $5^{\text {th }}$ ed., pp. 779-862). New York: Wiley.

Coie, J. D., Dodge, K. A., \& Coppotelli, H. (1982). Dimensions and types of social status: A cross-age perspective. Developmental Psychology, 18, 557-569.

Crick, N. R. (1997). Engagement in gender normative versus nonnormative forms of aggression: Links to social-psychological adjustment. Developmental Psychology, 33(4), 610-616.

Crick, N. R., \& Bigbee, M. A. (1998). Relational and overt forms of peer victimization: A multiinformant approach. Journal of Consulting and Clinical Psychology, 66(2), $337-347$.

Crick, N. R., \& Dodge, K. A. (1994). A review and reformulation of social informationprocessing mechanisms in children's social adjustment. Psychological Bulletin, $115(1), 74-101$.

Crick, N. R., \& Grotpeter, J. K. (1995). Relational aggression, gender, and socialpsychological adjustment. Child Development, 66, 710-722.

Degirmencioglu, S. M., Urberg, K. A., Tolson, J. M, \& Richard, P. (1998). Adolescent friendship networks: Continuity and change over the school year. Merrill-Palmer Quarterly, 44(3), 313-337.

Dodge, K. A., \& Coie, J. D. (1987). Social-information-processing factors in reactive and proactive aggression in children's peer groups. Journal of Personality and Social 
Psychology, 53, 1386-1399.

Dodge, K. A., Coie, J. D., Pettit, G. S., \& Price, J. M. (1990). Peer status and aggression in boys' groups: Developmental and contextual analyses. Child Development, $61(5), 1289-1309$.

Eder, D. (1985). The cycle of popularity: Interpersonal relations among female adolescents. Sociology of Education, 58(3), 154-165.

Eder, D., Evans, C. C., \& Parker, S. (1995). School talk: Gender and adolescent culture. New Brunswick, NJ: Rutgers University Press.

Eisenberg, N. \& Mussen, P. H. (1989). The roots of prosocial behavior in children. Cambridge: Cambridge University Press.

Farmer, T. W., Estell, D. B., Bishop, J. L., O’Neal, K. K., \& Cairns, B. D. (2003). Rejected bullies or popular leaders? The social relations of aggressive subtypes or rural African American early adolescents. Developmental Psychology, 39(6), 9921004.

Feingold, A. (1992). Good-looking people are not what we think. Psychological Bulletin, $111,304-311$.

Galen, B. R., \& Underwood, M. K. (1997). A developmental investigation of social aggression among children. Developmental Psychology, 33(4), 589-600.

Grotpeter, J. K., \& Crick, N. R. (1996). Relational aggression, overt aggression and friendship. Child Development, 67, 2328-2338.

Hartup, W. W. (1974). Aggression in childhood: Developmental perspectives. American Psychologist, 29, 336-341.

Hawley, P. H. (1999). The ontogenesis of social dominance: A strategy-based 
evolutionary perspective. Developmental Review, 19, 97-132.

Hawley, P. H. (2001, April). Coercive strategies of resource control in preadolescents: Maladaptation vs. Machiavellianism. Paper presented at the biennial meeting of the Society for Research on Adolescence, Minneapolis, MN.

Hawley, P. H. (2002). Social dominance and prosocial and coercive strategies of resource control in preschoolers. International Journal of Behavioral Development, 26(2), $167-176$.

Hawley, P. H. (2003a). Strategies of control, aggression, and morality in preschoolers: An evolutionary perspective. Journal of Experimental Child Psychology, 85, 213235.

Hawley, P. H. (2003b). Prosocial and coercive configurations of resource control in early adolescence: A case for the well-adapted Machiavellian. Merrill-Palmer Quarterly, 49(3), 279-309.

Hawley, P. H., Little, T. D., \& Pasupathi, M. (2002). Winning friends and influencing peers: Strategies of peer influence in late childhood. International Journal of Behavioral Development, 26(5), 466-474.

Heilman, E. E. (1998). The struggle for self: Power and identity in adolescent girls. Youth \& Society, 30(2), 182-208.

Hopmeyer Gorman, A., Kim, J., \& Schimmelbusch, A. (2002). The attributes adolescents associate with peer popularity and teacher preference. Journal of School Psychology, 40(2), 143-165.

Hussong, A. M. (2002). Differentiating peer contexts and risk for adolescent substance use. Journal of Youth and Adolescence, 31(3), 207-220. 
Koop, V., \& Hawley, P. H. (2004, March). Bistrategic adolescent friendships: How employing aggressive and prosocial behavior affect friendship quality. Paper presented at the biennial meeting of the Society for Research on Adolescence, Baltimore, MD.

Kosir, K., \& Pecjak, S. (2005). Sociometry as a method for investigating peer relationships: what does it actually measure? Educational Research, 47(1), 127144.

La Fontana, K. M., \& Cillessen, A. H. N. (1999). Children's interpersonal perceptions as a function of sociometric and peer-perceived popularity. Journal of Genetic Psychology, 160, 225-242.

La Fontana, K. M., \& Cillessen, A. H. N. (2002). Children's perceptions of popular and unpopular peers: A multimethod assessment. Developmental Psychology, 38(5), 635-647.

La Freniere, P., \& Charlesworth, W. R. (1983). Dominance, attention, and affiliation in a preschool group: A nine-month longitudinal study. Ethology and Sociobiology, 4, $55-67$.

Lagerspetz, K. M. J., Bjorkqvist, K., Berts, M., \& King, E. (1982). Group aggression among school children in three schools. Scandanavian Journal of Psychology, 23, $45-52$.

Lease, A. M., Kennedy, C. A., \& Axelrod, J. L. (2002). Children's social constructions of popularity. Social Development, 11(1), 87-109.

Lease, A. M., Musgrove, K. T., \& Axelrod, J. L. (2002). Dimensions of social status in preadolescent peer groups: likability, perceived popularity, and social dominance. 
Social Development, 11(4), 508-533.

Little, T. D., Brauner, J., Jones, S. M., Nock, M. K., \& Hawley, P. H. (2003). Rethinking aggression: A typological examination of the functions of aggression. MerrillPalmer Quarterly, 49(3), 343-369.

Little, T. D., \& Card, N. A. (2004, March). Gender differences in the links among friendship characteristics and aggressive behavior. Paper presented at the biennial meeting of the Society for Research on Adolescence, Baltimore, MD.

Little, T. D., Jones, S. M., Henrich, C. C., \& Hawley, P. H. (2003). Disentangling the "whys" from the "whats" of aggressive behaviour. International Journal of Behavioral Development, 27(2), 122-133.

Maccoby, E. E., \& Jacklin C. N. (1974). The Psychology of Sex Differences. Stanford, CA: Stanford University Press.

Merten, D. E. (1997). The meaning of meanness: Popularity, competition, and conflict among junior high school girls. Sociology of Education, 70, 175-191.

Merten, D. E. (2004). Securing her experience: Friendship versus popularity. Feminism \& Psychology, 14(3), 361-365.

Newcomb, A. F., Bukowski, W. M., \& Pattee, L. (1993). Children's peer relations: A meta-analytic review of popular, rejected, neglected, controversial, and average sociometric status. Psychological Bulletin, 113, 99-128.

Nukulkij, P., Cillessen, A. H. N., Bellmore, A. D., Whitcomb, M. E., \& Burke, J. D. (2002). Sociometric status in early adolescence: Stability and behavioral correlates. Unpublished manuscript, University of Connecticut, Storrs.

Parker, J. G., \& Asher, S. R. (1993). Friendship and friendship quality in middle 
childhood: Links with peer group acceptance and feelings of loneliness and social dissatisfaction. Developmental Psychology, 29(4), 611-621.

Parkhurst, J. T., \& Hopmeyer, A. (1998). Sociometric popularity and peer-perceived popularity: Two distinct dimensions of peer status. Journal of Early Adolescence, $18,125-144$.

Paxton, S. J., Schutz, H. K., Wertheim, E. H., \& Muir, S. L. (1999). Friendship clique and peer influences on body image concerns, dietary restraint, extreme weight-loss behaviors and binge eating in adolescent girls. Journal of Abnormal Psychology, $108(2), 255-266$.

Pellegrini, A. D., Bartini, M., \& Brooks, F. (1999). School bullies, victims, and aggressive victims: Factors relating to group affiliation and victimization in early adolescence. Journal of Educational Psychology, 91(2), 216-224.

Price, J. M., \& Dodge, K. A. (1989). Reactive and proactive aggression in childhood: Relations to peer status and social context dimensions. Journal of Abnormal Child Psychology, 17(4), 455-471.

Prinstein, M. J. (2001). Aggression to protect one's status among peers: forms and functions of adolescent aggressive behavior in a social context. Unpublished manuscript.

Prinstein, M. J., Boergers, J., Vernberg, E. M. (2001). Overt and relational aggression in adolescents: Social-psychological adjustment of aggressors and victims. Journal of Clinical Child Psychology, 30, 479-491.

Prinstein, M. J., \& Cillessen, A. H. N. (2003). Forms and functions of adolescent peer aggression associated with high levels of peer status. Merrill-Palmer Quarterly, 
49(3), 310-342.

Rodkin, P. C., Farmer, T. W., Pearl, R., \& Van Acker, R. (2000). Heterogeneity of popular boys: Antisocial and prosocial configurations. Developmental Psychology, $36,14-24$.

Rose, A. J., Swenson, L. P., \& Carlson, W. (2004). Friendships of aggressive youth. Considering the influences of being disliked and of being perceived as popular. Journal of Experimental Child Psychology, 88, 25-45.

Rose, A. J., Swenson, L. P., \& Waller, E. M. (2004). Overt and relational aggression and perceived popularity: Developmental differences in concurrent and prospective relations. Developmental Psychology, 40(3), 378-387.

Rubin, K. H., Bukowski, W. M., \& Parker, J. G. (1998). Peer interactions, relationships, and groups. In W. Damon \& N. Eisenberg (Eds.), Handbook of child psychology (pp. 619-700). New York: Springer Verlag.

Rubin, K. H., \& Rose-Krasnor, L. (1992). Interpersonal problem solving. In V. B. V. Hassett \& M. Hersen (Eds.), Handbook of social development (pp. 283-323). New York: Plenum.

Savin-Williams, R. C. (1979). Dominance hierarchies in groups of early adolescents. Child Development, 50(4), 923-935.

Savin-Williams, R. C. (1980). Dominance hierarchies in groups of middle to late adolescent males. Journal of Youth and Adolescence, 9, 75-85.

Savin-Williams, R. C., \& Freedman, D. G. (1977). Bio-social approach to human development. In S. Chevalier-Skolnikoff \& F. E. Poirier (Eds.), Primate bio-social development: biological, sociological, and ecological determinants. New York: 
Garland.

Strayer, F. F., \& Strayer, J. (1976). An ethological analysis of social agonism and dominance relations among preschool children. Child Development, 47, 980-989.

Strayer, F. F., \& Trudel, M. (1984). Developmental changes in the nature and function of social dominance among young children. Ethology and Sociobiology, 5, 279-295.

Terry, R. (2000). Recent advances in measurement theory and the use of sociometric techniques. In W. Damon (Series Ed.) and A. H. N. Cillessen \& W. M. Bukowski (Vol. Eds.), New directions for child and adolescent development: No. 88. Recent advances in the measurement of acceptance and rejection in the peer system (pp. 27-54). San Francisco, CA: Jossey-Bass.

Thompson, M., O’Neill Grace, C., \& Cohen, L. J. (2001). Best friends, worst enemies: Understanding the social lives of children. New York, NY: Ballantine Publishing Group.

Tomada, G., \& Schneider, B. H. (1997). Relational aggression, gender, and peer acceptance: Invariance across culture, stability over time, and concordance among informants. Developmental Psychology, 33, 601-609.

Trivers, R. L. (1971). The evolution of reciprocal altruism. Quarterly Review of Biology, $46,35-57$.

Underwood, M. K., Galen, B. R., \& Paquette, J. A. (2001). Top ten challenges for understanding gender and aggression in children: Why can't we all just get along? Social Development, 10, 248-266.

Vaillancourt, T., Hymel, S., \& McDougall, P. (2003). Bullying is power: Implications for school-based intervention strategies. Journal of Applied School Psychology, 19, 
$157-176$.

Xie, H., Cairns, R. B., Cairns, B. D. (1999). Social networks and configurations in innercity schools: Aggression, popularity, and implications for students with EBD.

Journal of Emotional and Behavior Disorders, 7, 147-155. 


\section{Appendix A \\ Informed Consent Letter for Parents/Guardians}

Dear Parents/Guardians,

Adolescents' social experiences play a crucial role in development. Both positive and negative aspects of relationships with peers affect young people in their daily life, as well as in the long term. One of the most important relationships at this age are those with friends. Friends can provide essential social support such as understanding, companionship, and guidance outside of the family setting.

A research study concerning adolescents' relationships with friends will be taking place at your child's school in December. This study will examine the social experiences that friends share, some of which are positive (e.g., help and support) as well as those that are sometimes problematic (e.g., conflict). Two important questions to be answered by this research are: (1) do the positive aspects of friendships outweigh any negative experiences? and (2) do adolescents enjoy their friendships despite the occasional episode of minor conflict?

Please indicate on the attached consent form whether you choose to have your child participate. All adolescents who promptly return their consent forms, whether or not they agree to participate, will be entered into a draw to win an MP3 player. As well, classrooms in which all students return consent forms, regardless of whether or not they will participate in the study, will receive a pizza party. Adolescents who choose to participate in this study will be asked to fill out a questionnaire during a group session in his/her regular classroom. This questionnaire will include questions regarding adolescents' friendships. The administration of the questionnaire will take approximately 45-60 minutes to complete.

This project has been approved by the Carleton University Research Ethics Committee for Psychological Research and the principal of your child's school. All information collected for this study is completely confidential and anonymous. Questionnaires will be reviewed only by the researcher and will be used only to extract data for study and data analysis. Study results will be reported in ways that ensure complete confidentiality of individual participants, and will not appear in any school records. General group results of the study will be available to both school officials and interested parents once the research study is completed.

Participation in this study is completely voluntary and your child may choose to withdraw, or decline to answer certain questions, without penalty, at any time during the study. Additionally, only students with parental permission will be allowed to participate. Whether or not you wish to have your child participate in this study, please complete the attached form and have your child return it to his/her homeroom teacher as soon as possible. If you have any questions, please feel free to use the contact information listed below. Should you have any ethical concerns regarding this study, please contact Dr. Janet Mantler (Chair, Carleton University Research Ethics Committee for Psychological Research; janet_mantler@carleton.ca; 613-520-2600, ext. 4173). Should you have any other concerns about this study, please contact Dr. Mary Gick (Chair, Department of Psychology; mary_gick@carleton.ca; 613-520-2600, ext. 2648).

Sincerely,

Leanna Closson, M. A. Student

Tina Daniels, Ph.D., Associate Professor tdaniels@ccs.carleton.ca

613-520-2600 ext. 2686 
Appendix B

Parent/Guardian Consent Form

\section{CONSENT FORM}

The information collected for this project is confidential and protected under the Municipal Freedom of Information and Protection of Privacy Act, 1989.

I have read and understood the request for my son/daughter to participate in the study of adolescents' friendships. I have discussed it with my son/daughter and...

I give permission for my child to participate

I do not give permission for my child to participate

Date:

Name of Child:

$$
\text { (please print) }
$$

Age: Grade:

Name of Parent or Guardian:

(please print)

Signature of Parent or Guardian:

\section{Please have your child return this signed consent form to his/her homeroom teacher by November 29. Thank you.}


Appendix C

Oral Instructions for Students

\section{Introduction}

Hello. My name is Leanna Closson. I came here today to ask your help with a project I am working on at my school. I would like to find out about how kids your age think about different things, and how you get along with your friends. I am going to ask you to help me by filling out some questionnaires. It is very important that you be as quiet as you can.

\section{Non-Participating Students}

Before we start, I have to tell you a few things. First, some of you will not be filling out the questionnaires. Do you remember those letters you brought home to your parents last week or the week before? Some of you didn't bring them back but most of you did. Only those students who brought them back with your parents marking "yes" - that it is okay for you to do this - only those students will fill out the questionnaires. I'll read off a list of those students who can not fill out the questionnaires. If I read your name, I'd like you to take out a book or some other work to do while the rest of us are filling out the questionnaires (or go to the library if the teacher permits). OK?

\section{Confidentiality}

One thing you should know is this is not a test. You won't be graded. In fact, there are no right or wrong answers to any of the questions. I think you'll find it kind of fun and interesting and it won't take up too much time. Now, for those of you filling out the questionnaires, I want you to know that all of your answers are confidential. That means that I won't show them to any of your classmates, parents, or teachers. So you can be honest when you write your answers. Because your answers are private, you should not talk to your classmates or look at other people's answers while you are filling out these questionnaires. And, just to be safe, you can use a piece of paper to cover your answers as you go along. If there are any questions that you don't feel comfortable answering, you don't have to answer them.

Here's how things will work. Before each questionnaire, we will read through the instructions together. At the end of each questionnaire there will be a picture of a stop sign. When you see the stop sign - stop and wait. We will continue to the next questionnaire once everyone has finished. We will do this for all of the questionnaires until the end. If anyone has any questions at any time, please raise your hand. We will be about 45 minutes to 1 hour.

OK. Is everybody ready to begin?

(Proceed to read instructions as written on each questionnaire.) 


\section{Appendix D}

\section{Oral Debriefing for Students}

I would like to thank you very much for helping me with my study today. I want to remind you that the things we talked about today are confidential. That means that I'm not going to share your answers to these questions with your teachers, parents, or other students. Also, I want you to know that you don't have to talk about these things with anyone either. Even if your classmates ask you about any of your answers, you don't have to tell them anything if you don't want to. But sometimes we all need to talk about the way that we feel. So, if you want to talk to someone about the questions you were asked today, or if you feel that you are having problems with other students at school, please talk to your parents or teachers about it. Today you answered some questions about your opinions of people in your grade. It is normal to like or hang around with certain people. But it is not okay to be mean or hurtful to anyone. We need to be sensitive to everybody's feelings, no matter if they are our friends or not.

I would like to give you a little bit more information about my study. As you know, friendships that you have with people at school can be a lot of fun. But sometimes people also have arguments or disagreements with their friends. What I'm trying to do is find out how people your age get along with each other, and why people sometimes do nice things for each other, but other times might do some "not-so-nice" things, like teasing or fighting. If researchers can find some answers to these questions then maybe we can find a way to help students when they have problems with their relationships, and help them to have great friendships. The answers that you have given us will help us to do this. So, I want to thank you very much for sharing your thoughts and opinions with me.

Does anyone have any questions about the survey we did today?

O.K. Thanks very much for your help. 


\section{Appendix E}

\section{Debriefing Letter for Parents/Guardians}

Dear Parents/Guardians,

We would like to take this opportunity to thank you for allowing your child to participate in this study regarding adolescents' friendships. The purpose of this study was to examine the nature of adolescent's relationships with friends. Research has shown that friendships can be positive at times, as well as problematic at other times. Friendships in general tend to be relatively positive experiences for children. However, there are times when even best friends experience conflict in their relationships. In fact, friendships can sometimes be used as a means for a child to hurt another peer or to get something that he or she wants. For example, past research has shown children to report that they have experienced a threat of friendship termination (e.g., If you don't do what I say, I'm not going to be friends with you anymore.). It is important to examine both positive and negative aspects of children's friendships if we are to fully understand the nature of those associations.

Also, we would like to remind you that all individual information collected from students is confidential and no individual results will be reported. Over the next several months, the information will be analyzed and a summary report based on all information from all schools will be written. This summary will be available to each participating school. If you would like a summary of the results of the study, or have any questions, please feel free to use the contact information listed below. Should you have any ethical concerns regarding this study, please feel free to contact Dr. Janet Mantler (Chair, Carleton University Research Ethics Committee for Psychological Research; janet_mantler@carleton.ca; 613-520-2600, ext. 4173). Should you have any other concerns about this study, please contact Dr. Mary Gick (Chair, Department of Psychology; mary_gick@ carleton.ca; 613-520-2600, ext. 2648). Thank you for your assistance in this research project.

Sincerely, 
Appendix F

Questionnaire Packet Cover Page

\section{The Friendship Survey}

Thank you for participating in this study. The following package contains a number of questions that will help me to understand students' relationships with each other. Your answers are completely private and will not be shared with anyone. Please read the directions for each questionnaire carefully. Even though some of the questions may look the same, it is important that you read and answer each question carefully.

Please complete the following information before you begin:

Name:

Birthday:

(month, day, and year you were born)

School:

Grade:

Today's Date:

Gender (circle one): Boy Girl 
Appendix G

Description of Popularity

\section{Popularity}

List up to 6 words that describe what it means to be popular:

1.

2.

3.

4.

5.

6. 
Appendix $\mathrm{H}$

Perceived Popularity

\section{Popularity}

Using the list of students in your grade, write down the students who you think are the most popular. Instead of writing their names, put the number that appears by each student's name.

1.

2.

3.

4.

5.

Using the list of students in your grade, write down the students who you think are the least popular. Instead of writing their names, put the number that appears by each student's name.

1.

2.

3.

4.

5.
10.

6.

7.

8.

9. 
Appendix I

Likeability and Visibility

\section{Liking}

Using the list of students in your grade, write down the students who you personally like the most. Instead of writing their names, put the number that appears by each student's name.

1.

2.

3.

4.

5. 10.

Using the list of students in your grade, write down the students who you personally like the least. Instead of writing their names, put the number that appears by each student's name.

1.

2.

3.

4.

5.

10.
6.

7.

8.

9. 


\author{
Appendix $\mathbf{J}$ \\ Group of Friends Identification
}

\title{
Who Are Your Friends?
}

(1) Using the list of students in your grade, find the students who are in the group of friends you hang around with most often. Write a " 1 " beside the name of the first friend on the list, a " 2 " beside the name of the second friend on the list and so on for up to $\underline{9}$ friends. Don't worry if your group has less than 10 people (including yourself), just pick however many are in your group. If your group has more than 10 people, pick $\underline{9}$ of your friends in the group you spend the most time with.

(2) Next, write down the friends in your group below. But instead of writing their names, put the ID number that appears by each friend's name on the list (the number that was already there, not the one you wrote). The person who's name you put a " 1 " beside on the list should be "Friend 1" below and so on. Don't put down yourself, just put the friends in your group. If there are friends in your group that are not on the list, write their initials.

(3) Beside each friend's number below, put an " $\mathrm{M}$ " if they are male or an " $\mathrm{F}$ " if they are female.

Friend's Number

Friend 1:

Friend 2:

Friend 3:

Friend 4:

Friend 5:

Friend 6:

Friend 7:

Friend 8 :

Friend 9:
Male or Female

( $M$ or $F$ ) 


\author{
Appendix K \\ Group of Friends Quesionnaire (Friend-Report)
}

\begin{abstract}
About Your Group of Friends
Now I would like you to tell me about your group of friends. Answer each question about every friend from the list (the ones you gave numbers to) in the group you identified on the last page. These questions are not about the other students in your class or grade, just your group of friends you hang around with most often. Rate how much each question describes each of your friends with numbers on the scale from 1 (Not At All Like My Friend) to 4 ( $A$ Whole Lot Like My Friend) by marking the box under one of the numbers. You can use any of the numbers on the scale. Be sure to give all of the friends with numbers a rating for each question. The friend you listed on the previous page as "Friend 1 " should be used as "Friend 1 " for these questions, and the same for "Friend 2 " and so on for all of the friends you listed in your group. Do not answer questions about friends you identified with initials. To make it easier, you can look at the list of students where you marked the numbers beside each of your friends' names. That way, you will know who is "Friend 1 " and "Friend 2 " and so on.
\end{abstract}

1. This friend has influence and power over our group of friends.

$\begin{array}{lcccc} & \text { Not At All } & & & \text { A Whole Lot } \\ \text { Friend 1 } & \mathbf{1} & \mathbf{2} & \mathbf{3} & \mathbf{4} \\ \text { Friend 2 } & \square & \square & \square & \square \\ \text { Friend 3 } & \square & \square & \square & \square \\ \text { Friend 4 } & \square & \square & \square & \square \\ \text { Friend 5 } & \square & \square & \square & \square \\ \text { Friend 6 } & \square & \square & \square & \square \\ \text { Friend 7 } & \square & \square & \square & \square \\ \text { Friend 8 } & \square & \square & \square & \square \\ \text { Friend 9 } & \square & \square & \square & \square\end{array}$

2. This friend helps someone in our group when they are having problems.

$\begin{array}{lcccc} & \text { Not At All } & & & \text { A Whole Lot } \\ \text { Friend 1 } & \mathbf{1} & \mathbf{2} & \mathbf{3} & \mathbf{4} \\ \text { Friend 2 } & \square & \square & \square & \square \\ \text { Friend 3 } & \square & \square & \square & \square \\ \text { Friend 4 } & \square & \square & \square & \square \\ \text { Friend 5 } & \square & \square & \square & \square \\ \text { Friend 6 } & \square & \square & \square & \square \\ \text { Friend 7 } & \square & \square & \square & \square \\ \text { Friend 8 } & \square & \square & \square & \square \\ \text { Friend 9 } & \square & \square & \square & \square\end{array}$


3. Someone in our group gossips or spreads rumours about this friend.

\section{Not At All}

1

Friend 1

Friend 2

Friend 3

Friend 4

Friend 5

Friend 6

Friend 7

Friend 8

Friend 9

\section{1}

$\square$

口

$\square$

$\square$

口

口

口

口
2

$\square$

$\square$

$\square$

$\square$

$\square$

$\square$

$\square$

$\square$

A Whole Lot

3

$\square$

口

口

口

口

$\square$

$\square$

ㅁ
4

ㅁ

$\square$

口

$\square$

$\square$

$\square$

$\square$

口

4. This friend hits, kicks, or punches someone in our group if they have angered him/her.

\section{Not At All}

\section{1}

Friend 1

Friend 2

Friend 3

Friend 4

Friend 5

Friend 6

Friend 7

Friend 8

Friend 9
ㅁ

$\square$

口

$\square$

$\square$

$\square$

$\square$

$\square$

$\square$
2

$\square$

$\square$

$\square$

$\square$

口

$\square$

口

口

口

A Whole Lot

3

$\square$

口

$\square$

$\square$

$\square$

$\square$

$\square$

$\square$

$\square$
4

$\square$

口

$\square$

$\square$

口

口

口

口

$\square$

5. To get what he/she wants, this friend tells others in our group to stop liking someone in our group.

$\begin{array}{lcccc} & \text { Not At All } & & & \text { A Whole Lot } \\ \text { Friend 1 } & \mathbf{1} & \mathbf{2} & \mathbf{3} & \mathbf{4} \\ \text { Friend 2 } & \square & \square & \square & \square \\ \text { Friend 3 } & \square & \square & \square & \square \\ \text { Friend 4 } & \square & \square & \square & \square \\ \text { Friend 5 } & \square & \square & \square & \square \\ \text { Friend 6 } & \square & \square & \square & \square \\ \text { Friend 7 } & \square & \square & \square & \square \\ \text { Friend 8 } & \square & \square & \square & \square \\ \text { Friend 9 } & \square & \square & \square & \square\end{array}$


6. This friend hits, kicks, or punches someone in our group to get what he/she wants.

Not At All

1

Friend 1

Friend 2

Friend 3

Friend 4

Friend 5

Friend 6

Friend 7

Friend 8

Friend 9

\section{$\square$}

$\square$

$\square$

$\square$

$\square$

口

$\square$

$\square$
2

$$
\begin{aligned}
& \square \\
& \square \\
& \square \\
& \square \\
& \square \\
& \square \\
& \square \\
& \square \\
& \square
\end{aligned}
$$

A Whole Lot

3

4

$\square$

$\square$

$\square$

$\square$

$\square$

$\square$

ㅁ.

$\square$

$\square$

7. I like to spend time with this friend.

$\begin{array}{lcccc} & \text { Not At All } & & & \text { A Whole Lot } \\ \text { Friend 1 } & \mathbf{1} & \mathbf{2} & \mathbf{3} & \mathbf{4} \\ \text { Friend 2 } & \square & \square & \square & \square \\ \text { Friend 3 } & \square & \square & \square & \square \\ \text { Friend 4 } & \square & \square & \square & \square \\ \text { Friend 5 } & \square & \square & \square & \square \\ \text { Friend 6 } & \square & \square & \square & \square \\ \text { Friend 7 } & \square & \square & \square & \square \\ \text { Friend 8 } & \square & \square & \square & \square \\ \text { Friend 9 } & \square & \square & \square & \square\end{array}$

8. If someone in our group upsets or hurts this friend, he/she tells others in our group to stop liking the person that hurt him/her.

$\begin{array}{lcccc} & \text { Not At All } & & & \text { A Whole Lot } \\ \text { Friend 1 } & \mathbf{1} & \mathbf{2} & \mathbf{3} & \mathbf{4} \\ \text { Friend 2 } & \square & \square & \square & \square \\ \text { Friend 3 } & \square & \square & \square & \square \\ \text { Friend 4 } & \square & \square & \square & \square \\ \text { Friend 5 } & \square & \square & \square & \square \\ \text { Friend 6 } & \square & \square & \square & \square \\ \text { Friend 7 } & \square & \square & \square & \square \\ \text { Friend 8 } & \square & \square & \square & \square \\ \text { Friend 9 } & \square & \square & \square & \square\end{array}$


9. This friend is nice to someone in our group when they need help.

Not At All

Friend 1

Friend 2

Friend 3

Friend 4

Friend 5

Friend 6

Friend 7

Friend 8

Friend 9
1

$\square$

$\square$

$\square$

$\square$

$\square$

$\square$

$\square$

$\square$

$\square$
2

$\square$

$\square$

$\square$

$\square$

$\square$

$\square$

$\square$

$\square$

$\square$
A Whole Lot

4

$\square$

ㅁ

$\square$

$\square$

ㅁ

口

ㅁ

$\square$

$\square$

10. This friend says mean things to someone in our group if he/she is hurt by them.

Friend 1

Friend 2

Friend 3

Friend 4

Friend 5

Friend 6

Friend 7

Friend 8

Friend 9

\section{Not At All}

1

$\square$

$\square$

$\square$

$\square$

$\square$

$\square$

$\square$

$\square$

$\square$
2

口

口

口

口

口

$\square$

口

$\square$

$\square$

A Whole Lot

3

$\square$

$\square$

$\square$

$\square$

口

$\square$

$\square$

$\square$

ㅁ

\section{4}

$\square$

$\square$

$\square$

$\square$

$\square$

$\square$

$\square$

$\square$

$\square$

11. When he/she needs help, someone in our group is nice to this friend.

$\begin{array}{lcccc} & \text { Not At All } & & & \text { A Whole Lot } \\ \text { Friend 1 } & \mathbf{1} & \mathbf{2} & \mathbf{3} & \mathbf{4} \\ \text { Friend 2 } & \square & \square & \square & \square \\ \text { Friend 3 } & \square & \square & \square & \square \\ \text { Friend 4 } & \square & \square & \square & \square \\ \text { Friend 5 } & \square & \square & \square & \square \\ \text { Friend 6 } & \square & \square & \square & \square \\ \text { Friend 7 } & \square & \square & \square & \square \\ \text { Friend 8 } & \square & \square & \square & \square \\ \text { Friend 9 } & \square & \square & \square & \square\end{array}$


12. Someone in our group tells others in our group to stop liking this friend.

\section{Not At All}

\section{1}

Friend 1

Friend 2

Friend 3

Friend 4

Friend 5

Friend 6

Friend 7

Friend 8

Friend 9

\section{口}

口

$\square$

$\square$

$\square$

口

$\square$

$\square$

口
2

\section{ㅁ}

$\square$

$\square$

$\square$

口

$\square$

$\square$

$\square$

口
A Whole Lot

3

4

$\square$

ㅁ

口

$\square$

$\square$

$\square$

口

口

$\square$

13. If this friend is mad at someone in our group, he/she gossips or spreads rumours about them.

$\begin{array}{lcccc} & \text { Not At All } & & & \text { A Whole Lot } \\ \text { Friend 1 } & \mathbf{1} & \mathbf{2} & \mathbf{3} & \mathbf{4} \\ \text { Friend 2 } & \square & \square & \square & \square \\ \text { Friend 3 } & \square & \square & \square & \square \\ \text { Friend 4 } & \square & \square & \square & \square \\ \text { Friend 5 } & \square & \square & \square & \square \\ \text { Friend 6 } & \square & \square & \square & \square \\ \text { Friend 7 } & \square & \square & \square & \square \\ \text { Friend 8 } & \square & \square & \square & \square \\ \text { Friend 9 } & \square & \square & \square & \square\end{array}$

14. I like this friend.

$\begin{array}{lcccc} & \text { Not At All } & & & \text { A Whole Lot } \\ \text { Friend 1 } & \mathbf{1} & \mathbf{2} & \mathbf{3} & \mathbf{4} \\ \text { Friend 2 } & \square & \square & \square & \square \\ \text { Friend 3 } & \square & \square & \square & \square \\ \text { Friend 4 } & \square & \square & \square & \square \\ \text { Friend 5 } & \square & \square & \square & \square \\ \text { Friend 6 } & \square & \square & \square & \square \\ \text { Friend 7 } & \square & \square & \square & \square \\ \text { Friend 8 } & \square & \square & \square & \square \\ \text { Friend 9 } & \square & \square & \square & \square\end{array}$


15. This friend gets hit, kicked, or punched by someone in our group.

$\begin{array}{lcccc} & \text { Not At All } & & & \text { A Whole Lot } \\ \text { Friend 1 } & \mathbf{1} & \mathbf{2} & \mathbf{3} & \mathbf{4} \\ \text { Friend 2 } & \square & \square & \square & \square \\ \text { Friend 3 } & \square & \square & \square & \square \\ \text { Friend 4 } & \square & \square & \square & \square \\ \text { Friend 5 } & \square & \square & \square & \square \\ \text { Friend 6 } & \square & \square & \square & \square \\ \text { Friend 7 } & \square & \square & \square & \square \\ \text { Friend 8 } & \square & \square & \square & \square \\ \text { Friend 9 } & \square & \square & \square & \square\end{array}$

16. This friend says mean things to someone in our group to get what he/she wants.

$\begin{array}{lcccc} & \text { Not At All } & & & \boldsymbol{A} \text { Whole Lot } \\ \text { Friend 1 } & \mathbf{1} & \mathbf{2} & \mathbf{3} & \mathbf{4} \\ \text { Friend 2 } & \square & \square & \square & \square \\ \text { Friend 3 } & \square & \square & \square & \square \\ \text { Friend 4 } & \square & \square & \square & \square \\ \text { Friend 5 } & \square & \square & \square & \square \\ \text { Friend 6 } & \square & \square & \square & \square \\ \text { Friend 7 } & \square & \square & \square & \square \\ \text { Friend 8 } & \square & \square & \square & \square \\ \text { Friend 9 } & \square & \square & \square & \square\end{array}$

17. This friend gets people in our group to do what he/she wants.

Not At All

Friend 1

Friend 2

Friend 3

Friend 4

Friend 5

Friend 6

Friend 7

Friend 8

Friend 9
1

2

$\square$

$\square$

$\square$

$\square$

$\square$

$\square$

$\square$

$\square$
A Whole Lot

3

口

4

$\square$

ㅁ

$\square$

口

口

$\square$

$\square$

$\square$ 
18. To get what he/she wants, this friend gossips or spreads rumours about someone in our group.

$\begin{array}{lcccc} & \text { Not At All } & & & \text { A Whole Lot } \\ \text { Friend 1 } & \mathbf{1} & \mathbf{2} & \mathbf{3} & \mathbf{4} \\ \text { Friend 2 } & \square & \square & \square & \square \\ \text { Friend 3 } & \square & \square & \square & \square \\ \text { Friend 4 } & \square & \square & \square & \square \\ \text { Friend 5 } & \square & \square & \square & \square \\ \text { Friend 6 } & \square & \square & \square & \square \\ \text { Friend 7 } & \square & \square & \square & \square \\ \text { Friend 8 } & \square & \square & \square & \square \\ \text { Friend 9 } & \square & \square & \square & \square\end{array}$

19. Someone in our group says mean things to this friend.

$\begin{array}{lrccc} & \text { Not At All } & & & \text { A Whole Lot } \\ \text { Friend 1 } & \mathbf{1} & \mathbf{2} & \mathbf{3} & \mathbf{4} \\ \text { Friend 2 } & \square & \square & \square & \square \\ \text { Friend 3 } & \square & \square & \square & \square \\ \text { Friend 4 } & \square & \square & \square & \square \\ \text { Friend 5 } & \square & \square & \square & \square \\ \text { Friend 6 } & \square & \square & \square & \square \\ \text { Friend 7 } & \square & \square & \square & \square \\ \text { Friend 8 } & \square & \square & \square & \square \\ \text { Friend 9 } & \square & \square & \square & \square\end{array}$

20. When he/she is having problems, someone in our group helps this friend.

Not At All

\section{1}

Friend 1

Friend 2

Friend 3

Friend 4

Friend 5

Friend 6

Friend 7

Friend 8

Friend 9

$$
1
$$

2

\section{$\square$}

ㅁ

$\square$

$\square$

$\square$

$\square$

口

$\square$

口
A Whole Lot

\section{3}

口

ㅁ

口

$\square$

$\square$

$\square$

$\square$

$\square$
4

$\square$

$\square$

$\square$

$\square$

$\square$

$\square$

$\square$

$\square$

$\square$ 
Appendix L

Group of Friends Questionnaire (Self-Report)

\begin{abstract}
About You
Now I would like you to tell me about the experiences you have with your group of friends (the same group you rated in the last questionnaire). Rate how much each question describes yourself on the scale from 1 (Not At All Like Me) to 4 ( $A$ Whole Lot Like Me) by marking the box under one of the numbers. You can use any of the numbers on the scale.
\end{abstract}

1. I have influence and power over my group of friends.

Not At All

1

口
2

$\square$

A Whole Lot

2. I help someone in my group of friends when they are having problems.

Not At All

1

$\square$
2

3

$\square$

A Whole Lot

4

3. Someone in my group of friends gossips or spreads rumours about me.

Not At All

1

$\square$
2

$\square$
3

A Whole Lot

4

4. I hit, kick, or punch someone in my group of friends if they have angered me.

Not At All

1

2

3

A Whole Lot

$\square$

$\square$

$\square$
4

$\square$

5. To get what I want, I tell others in my group of friends to stop liking someone in our group.

Not At All

1

$\square$
2

3

A Whole Lot 
6. I hit, kick, or punch someone in my group of friends to get what I want.

Not At All

1
2
A Whole Lot

4

7. People in my group of friends like to spend time with me.

Not At All

1

2

3

A Whole Lot

ㅁ
4

ㅁ

8. If someone in my group of friends upsets or hurts me, I tell others in my group to stop liking the person that hurt me.

Not At All

1

2

3

A Whole Lot

$\square$

4

$\square$

9. I am nice to someone in my group of friends when they need help.

Not At All

1
2
3

A Whole Lot

4

10. I say mean things to someone in my group of friends if I am hurt by them.

Not At All

1

2

3

A Whole Lot

1

11. When I need help, someone in my group of friends is nice to me.
Not At All

1

2

3

A Whole Lot

$\square$ $\square$

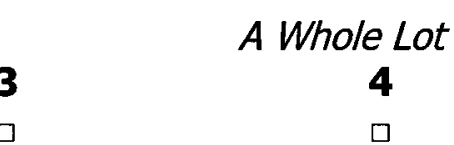

12. Someone in my group of friends tells others in our group to stop liking me.

Not At A/I

A Whole Lot
1

2

3

口

4

13. If I am mad at someone in my group of friends, I gossip or spread rumours about them.

Not At All

1

2

3

A Whole Lot ( 
14. People in my group of friends like me.

Not At All

1

2

3

A Whole Lot

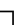

$\square$

$\square$

4

15. I get hit, kicked, or punched by someone in my group of friends.

Not At All

1

2

3

A Whole Lot

ㅁ

口

ㅁ

4

16. I say mean things to someone in my group of friends to get what I want.

Not At All

1

2

3

A Whole Lot

$\square$

$\square$

17. I get people in my group of friends to do what I want.

Not At All

1
2

$\square$

A Whole Lot

18. To get what I want, I gossip or spread rumours about someone in my group of friends.

Not At All

1

口
2

$\square$
3

a

A Whole Lot

4

19. Someone in my group of friends says mean things to me.

Not At All

1

$\square$
2

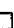

3

A Whole Lot

4

20. When I am having problems, someone in my group of friends helps me.

Not At All

1

2

3

A Whole Lot

4

$\square$

$\square$

The End.

Thank you for completing this survey!

(:) 
Appendix M

Directory of Items in the Group of Friends Questionnaire

$\underline{\text { Subscales }}$

Social Dominance

Friend Likeability

Prosocial Behaviour (given)

Prosocial Behaviour (received)

Instrumental Overt Aggression

Instrumental Relational Aggression

Reactive Overt Aggression

Reactive Relational Aggression

Overt Victimization

Relational Victimization
Item Numbers *

1,17

7,14

2,9

11,20

6,16

5,18

4,10

8,13

15,19

3,12

* Item numbers correspond with the items as they appear in the Group of Friends

Questionnaire (Friend-Report) and (Self-Report) (Appendix K and L, respectively) 